\title{
MOBILIDADE DO CRÔMIO ADICIONADO A DOIS LATOSSOLOS NA FORMA DE SAIS INORGÂNICOS E DE RESÍDUO DE CURTUME
}

\author{
ERIKA MANGILI ANDRÉ
}

Engenheiro Agrônomo

Orientadora: $\operatorname{Prof}^{\mathrm{a}} \mathrm{Dr}^{\mathrm{a}}$ MARIA EMILIA MATTIAZZO-PREZOTTO

Dissertação apresentada à Escola Superior de Agricultura "Luiz de Queiroz", Universidade de São Paulo, para obtenção do título de Mestre em Agronomia, Área de Concentração: Solos e Nutrição de Plantas.

PIRACICABA

Estado de São Paulo - Brasil

Setembro - 1997 
Dados Internacionais de Catalogação na Publicação (CIP)

DIVISÃo DE BIBLIOTECA E DOCUMENTAÇÃo - Campus "Luiz de Queiroz"/USP

André, Erika Mangili

Mobilidade do crômio adicionado a dois latossolos na forma de sais inorgânicos e de resíduo. de curtume / Erika Mangili Andrè. - - Piracicaba, 1997.

49 p. : il.

Dissertação (mestrado) - Escola Superior de Agricultura Luiz de Queiroz, 1997. Bibliografia.

1. Latossolos 2. Lixiviação 3. Metal pesado em solo 4. Residuo de curtume em solo I. Título 
MOBILIDADE DO CRÔMIO ADICIONADO A DOIS LATOSSOLOS NA FORMA DE SAIS INORGÂNICOS E DE RESÍDUO DE CURTUME

\author{
ERIKA MANGILI ANDRÉ
}

Aprovada em: 27.10.1997

Comissão julgadora:

Prof $\mathrm{Dr}^{\mathrm{a}}$ Maria Emilia Mattiazzo-Prezotto

ESALQ/USP

Prof. Dr. Luis Reynaldo Ferracciú Alleoni ESALQ/USP

Prof. Dr. Francisco José Krug

CENAUSP

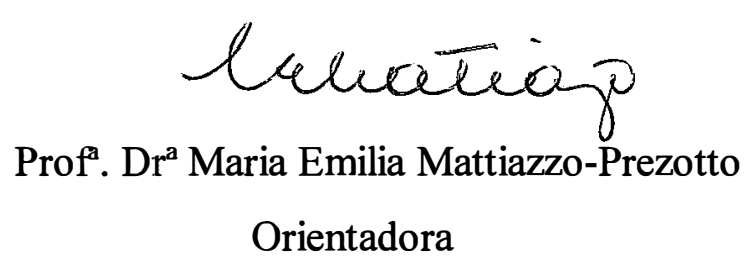


Aos meus pais, Romisio e Leda, pela vida e por todo amor,

DEDICO

Aos meus irmãos, Marcelo e Ana Paula, pela amizade e compreensão, OFEREÇO

"É preciso amar as pessoas como se não houvesse amanhã por que se você parar prá pensar na verdade não há...” (Renato Russo) 


\section{AGRADECIMENTOS}

- À Prof ${ }^{a} \operatorname{Dr}^{\mathrm{a}}$ Maria Emilia Mattiazzo-Prezotto, pelo apoio, amizade, e orientação;

- Aos professores da FCAV / UNESP Wanderley José de Melo, Manoel Evaristo Ferreira e Mara Cristina Pessôa da Cruz, pela atenção, sugestões e condições oferecidas para a realização desse trabalho;

- À Fundação de Amparo à Pesquisa do Estado de São Paulo (FAPESP), pelo apoio financeiro;

- Ao Prof. Dr. Sérgio do Nascimento Kronka da FCAV / UNESP, pelo auxílio nas análises estatísticas;

- À Prof Teresa Cristina Berchieri, pela correção do Summary;

- À Prof Glória Benedini Brusadin, pela revisão do trabalho;

- Aos técnicos de laboratório Roberto Aparecido Chelli, Sueli Aparecida Sangalli Leite e Selma Guimarães Figueiredo, pela ajuda na realização das análises químicas;

- Às colegas de curso Edna Bertoncini e Daniela Caldeira, pela amizade e por todos os momentos que passamos juntas;

- À bibliotecária Kátia Maria de Andrade Ferraz, pela correção das citações bibliográficas;

- A todos que direta ou indiretamente colaboraram para a realização desse trabalho. 


\section{SUMÁRIO}

Página

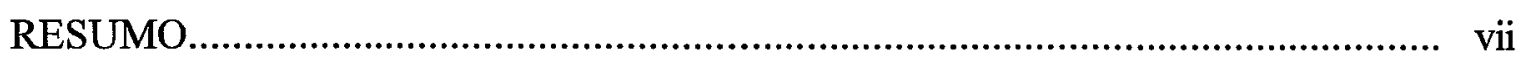

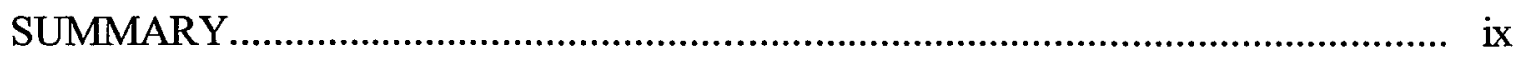

1 INTRODUÇÃO............................................................................... 1

2 REVISÃO DE LITERATURA................................................................... 3

2.1 Crômio no solo................................................................................ 3

2.2 Resíduo de curtume........................................................................... 7

2.3 Métodos para análise de crômio............................................................ 8

2.4 Biodegradabilidade de resíduos............................................................ 10

3 MATERIAL E MÉTODOS...................................................................... 12

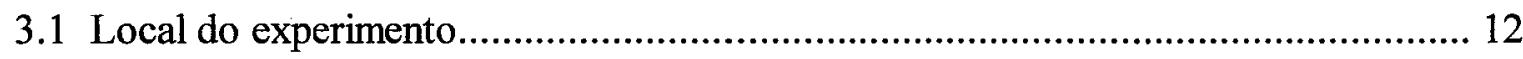

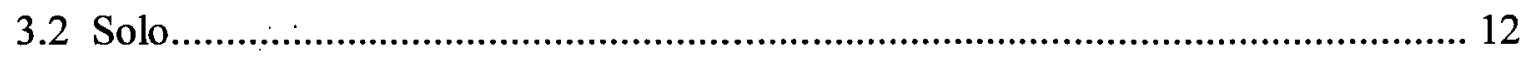

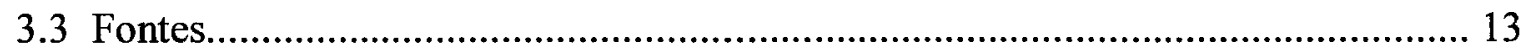

3.4 Resíduo de curtume............................................................................. 13

3.5 Estudo da biodegradabilidade do resíduo................................................. 15

3.6 Teste de extratores para análise de crômio em solos.................................... 16

3.6.1 Determinação do crômio hexavalente....................................................... 18

3.7 Movimentação de crômio em colunas de solo.............................................. 18

3.7.1 Determinação do crômio total........................................................... 19 


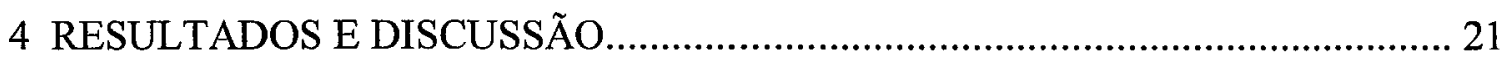

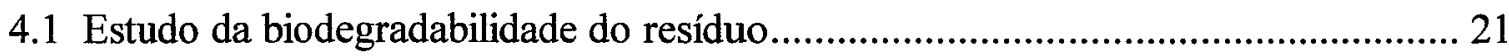

4.2 Teste de extratores para análise de crômio em solos............................................. 27

4.3 Movimentação de crômio em colunas de solo........................................................... 30

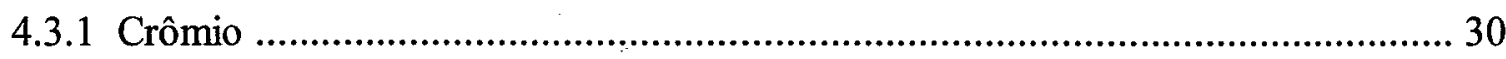

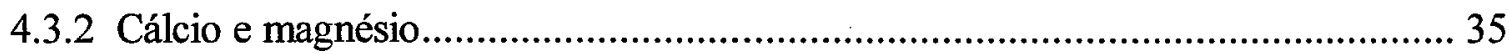

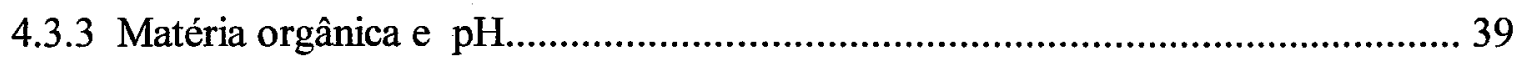

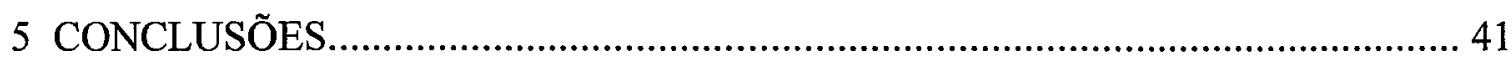

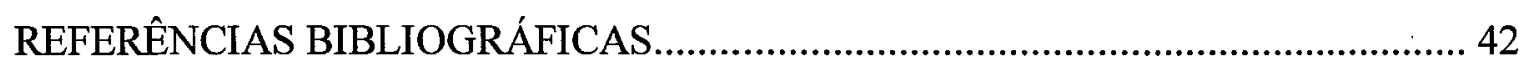

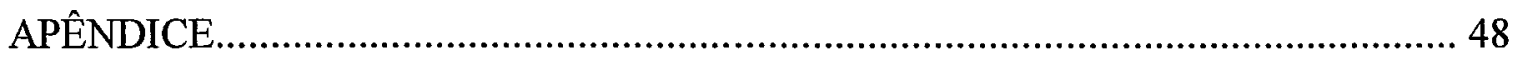




\title{
MOBILIDADE DO CRÔMIO ADICIONADO A DOIS LATOSSOLOS NA FORMA DE SAIS INORGÂNICOS E DE RESÍDUO DE CURTUME
}

\author{
Autora: ERIKA MANGILI ANDRÉ \\ Orientadora: Prof ${ }^{a} \operatorname{Dr}^{\mathrm{a}}$ MARIA EMILIA MATTIAZZO-PREZOTTO
}

\section{RESUMO}

$\mathrm{O}$ presente trabalho de pesquisa teve por objetivo principal avaliar o comportamento do crômio em dois latossolos, através do estudo da movimentação do metal em colunas de solo. Para complementar esse estudo, foi feita a avaliação da biodegradabilidade do resíduo de curtume contendo altas concentrações de crômio e testes de extratores para a determinação de crômio do solo. Os solos utilizados nos experimentos, cujas amostras foram submetidas a análises granulométrica e química, foram: Latossolo Roxo e Latossolo Vermelho Amarelo. Os solos foram incubados com resíduo de curtume e os sais $\mathrm{CrCl}_{3} .6 \mathrm{H}_{2} \mathrm{O}$ como fonte de $\mathrm{Cr}^{3+}$ e $\mathrm{K}_{2} \mathrm{Cr}_{2} \mathrm{O}_{7}$ como fonte de Cr(VI) para avaliar a mobilidade do crômio no solo e sua extração. A mobilidade do crômio foi avaliada em tubos de percolação nos quais realizou-se lixiviação, com análises do lixiviado e do solo. Os extratores testados para determinação de crômio solúvel foram: Mehlich 1, Mehlich 3, solução de $\mathrm{HCl} \mathrm{0,1} \mathrm{mol} \mathrm{L}{ }^{-1}$ e solução de $\mathrm{KH}_{2} \mathrm{PO}_{4}$. Os solos provenientes desses dois experimentos foram secos, peneirados $(2 \mathrm{~mm}$ de abertura de malha) e analisados para $\mathrm{Cr}(\mathrm{VI})$, matéria orgânica e pH. No experimento de mobilidade, 
o $\mathrm{Cr}^{3+}$ foi obtido pela diferença entre os teores de $\mathrm{Cr}$ total e $\mathrm{Cr}(\mathrm{VI})$. O estudo da biodegradabilidade do resíduo de curtume foi feito através da medida do $\mathrm{CO}_{2}$ liberado pela atividade dos microrganismos durante o processo de mineralização do material orgânico adicionado. Houve movimentação de crômio para a camada $20-40 \mathrm{~cm}$, principalmente quando o metal foi aplicado via sais inorgânicos; somente o crômio proveniente do tratamento com a fonte hexavalente foi detectado no lixiviado. Os teores de matéria orgânica do solo, após lixiviação, não sofreram grandes alterações e os valores de $\mathrm{pH}$ diminuíram em relação à testemunha, principalmente no LR, quando a fonte de crômio adicionada foi a trivalente (dose $1500 \mathrm{mg} \mathrm{kg}^{-1} \mathrm{Cr}$ ). Houve lixiviação de cálcio e magnésio, principalmente nos solos que receberam aplicação de crômio na forma trivalente. Grande parte do crômio hexavalente foi possivelmente reduzido a crômio trivalente ou adsorvido ao solo. Os extratores Mehlich 1, Mehlich 3 e $\mathrm{HCl} 0,1 \mathrm{~mol} \mathrm{~L}^{-1}$ apresentaram comportamento semelhante em relação à extração de crômio solúvel dos solos. O crômio não causou prejuízos aos microrganismos responsáveis pela degradação do resíduo de curtume aplicado aos solos. 


\section{MOBILITY OF CHROMIUM APPLIED TO TWO OXISOLS IN FORM OF \\ INORGANIC SALTS AND LEATHER WASTE}

Author: ERIKA MANGILI ANDRÉ

Adviser: Prof ${ }^{\mathrm{a}} \mathrm{Dr}^{\mathrm{a}}$ MARIA EMILIA MATTIAZZO-PREZOTTO

\section{SUMMARY}

This research was undertaken to assess the behavior of $\mathrm{Cr}$ in two Oxisols by studying its mobility in soil columns, to study the mineralization of organic carbon (as $\mathrm{CO}_{2}$ ) present in a leather processing industry residue containing $\mathrm{Cr}$ and to test extractants to determine soil soluble Cr. The soils used in these experiments were two Oxisols (Typic Eutrorthox and Typic Haplorthox). The inorganic salts $\mathrm{CrCl}_{3} \cdot 6 \mathrm{H}_{2} \mathrm{O}$ as a source of $\mathrm{Cr}^{3+}$ and $\mathrm{K}_{2} \mathrm{Cr}_{2} \mathrm{O}_{7}$ as a source of $\mathrm{Cr}(\mathrm{VI})$ and a leather processing industry containing $\mathrm{Cr}$ were used to evaluate the $\mathrm{Cr}$ mobility and extraction of chromium in the soil. Chromium mobility was evaluated by leaching in soil columns and the collected material was analysed for total $\mathrm{Cr}, \mathrm{Ca}$ and $\mathrm{Mg}$. The extractants tested for soil soluble $\mathrm{Cr}$ were: Mehlich 1, Mehlich 3, $\mathrm{HCl} 0,1 \mathrm{~mol} \mathrm{~L} \mathrm{~L}^{-1}$ and $\mathrm{KH}_{2} \mathrm{PO}_{4}$. The soil from these two experiments was sampled, dried, sifted (2 mm sieve) and analysed for $\mathrm{Cr}(\mathrm{VI})$, organic $\mathrm{C}$ and $\mathrm{pH}$. In the mobility study, $\mathrm{Cr}^{3+}$ was calculated by the difference between total $\mathrm{Cr}$ and $\mathrm{Cr}(\mathrm{VI})$. The study of $\mathrm{C}$ mineralization was carried out using only the residue and glucose 
to compare the results. The results showed that Mehlich 1, Mehlich 3 and $\mathrm{HCl} 0,1$ mol L ${ }^{-1}$ had the same behavior when extracted Cr. Most of $\mathrm{Cr}(\mathrm{VI})$ applied to the soil was reduced to $\mathrm{Cr}^{3+}$ or adsorbed. The soil $\mathrm{pH}$ decreased in soil that received $\mathrm{Cr}^{3+}(1500$ $\mathrm{mg} \mathrm{kg}^{-1} \mathrm{Cr}$ ). The application of $\mathrm{Cr}^{3+}$ and $\mathrm{Cr}(\mathrm{VI})$ salts had no effects on soil organic carbon. Cromium present in the residue applied to the soils did not seem to affect the soil microorganisms. 


\section{INTRODUÇÃo}

O crômio na crosta terrestre se encontra presente principalmente em rochas ultramáficas e máficas. A principal fonte de crômio é o mineral cromita, uma mistura de óxidos que pode conter de 42 a $56 \%$ de $\mathrm{Cr}_{2} \mathrm{O}_{3}, 10$ a $26 \%$ de $\mathrm{Fe}$ e quantidades variáveis de $\mathrm{Mg}$, $\mathrm{Al}$ e sílica.

As principais formas nas quais o crômio aparece no solo são: o cátion $\mathrm{Cr}^{3+} \mathrm{e}$ os anions $\mathrm{CrO}_{4}{ }^{2-} \mathrm{e}_{2} \mathrm{Cr}_{7}{ }^{2-}$ (Alloway, 1990).

$\mathrm{O}$ comportamento do $\mathrm{Cr}^{3+}$ é similar em muitos aspectos ao do $\mathrm{Fe}^{3+}$ e $\mathrm{Al}^{3+}$. Como o $\mathrm{Al}^{3+}, \mathrm{o} \mathrm{Cr}^{3+}$ é anfötero. Seu raio iônico é igual a $0,063 \mathrm{~nm}$, situado entre o do $\mathrm{Fe}^{3+}$ $(0,064 \mathrm{~nm})$ e o do $\mathrm{Al}^{3+}(0,051 \mathrm{~nm})$. O Cr${ }^{3+}$ é substituído facilmente por $\mathrm{Al}^{3+}$ em minerais de argila e outros silicatos, e também em outros minerais. Assim como o $\mathrm{Al}$, o crômio forma complexos catiônicos a baixos valores de $\mathrm{pH}$, hidróxidos insolúveis a $\mathrm{pH}$ próximo à neutralidade e complexos aniônicos a valores de $\mathrm{pH}$ acima da neutralidade. (KabataPendias \& Pendias, 1984).

Os compostos aniônicos de crômio em solos são tóxicos a plantas e animais. A forma hexavalente, simbolizada pelo íon $\mathrm{Cr}(\mathrm{VI})$, de raio 0,04 a $0,05 \mathrm{~nm}$, está quase sempre rodeada por ions oxigênio divalentes e, então, ligações covalentes são feitas entre o átomo central de crômio e os 4 oxigênios. Tanto o cromato $\left(\mathrm{CrO}_{4}{ }^{2-}\right)$ quanto o dicromato $\left(\mathrm{Cr}_{2} \mathrm{O}_{7}{ }^{2-}\right)$ são fixados muito fortemente por sítios de troca aniônica em minerais de argila. 
A variabilidade dos estados de oxidação do crômio em solos é de grande interesse ambiental, sendo o estado trivalente o mais estável. A forma trivalente de crômio é citada como sendo essencial à nutrição humana e animal (Bartlett \& Kimble, 1976a). Além disso, há necessidade de se avaliar o comportamento de crômio no solo, bem como a influência dos estados de oxidação e fatores que favorecem ou inibem a oxi-redução do elemento para a utilização racional desses resíduos.

Devido ao comportamento particular do crômio é necessário que sejam estabelecidos parâmetros que possibilitem o uso agrícola de resíduos contendo o elemento, sendo sua principal fonte antropogênica os resíduos de curtume. Para isso, há necessidade de se estabelecer(em) qual(is) é(são) o(s) extrator(es) mais eficiente(s) para crômio presente em solos e, também, de metodologia adequada para determinação das diferentes formas de crômio.

O objetivo do presente trabalho foi o estudo da movimentação de $\mathrm{Cr}^{3+}$ e $\mathrm{Cr}(\mathrm{VI})$ oriundos de sais inorgânicos e do crômio contido em resíduo de curtume adicionados em colunas de solo, assim como verificar os fatores que a afetam. Para complementar esse estudo, foram conduzidos outros dois experimentos, visando à avaliação da biodegradabilidade da fração orgânica do resíduo de curtume quando adicionado a solos e testes de extratores para a determinação de crômio no solo, respectivamente.

As hipóteses do presente trabalho foram as seguintes: movimentação do crômio no solo principalmente aplicado na forma hexavalente; oxidação do crômio trivalente pela presença de Mn nos solos; alteração do conteúdo de matéria orgânica e no valor $\mathrm{pH}$ dos solos pela aplicação de crômio; superioridade de um extrator sobre os demais na extração de crômio solúvel dos solos; degradação lenta do resíduo de curtume pela presença de crômio. 


\section{REVISÃO DE LITERATURA}

\subsection{Crômio no solo}

Na maioria dos solos o teor total de crômio está situado entre 5 e $1000 \mathrm{mg} \mathrm{kg}^{-1}$. Solos derivados de serpentina são conhecidos por conter cerca de 2,0 a $4,0 \mathrm{~g} \mathrm{~kg}^{-1} \mathrm{de}$ crômio. $\mathrm{O}$ teor médio mundial em solos é considerado como sendo $50 \mathrm{mg} \mathrm{kg}^{-1}$ de crômio (Alloway, 1990).

O comportamento do crômio no solo tem sido estudado por vários autores. Kabata-Pendias \& Pendias (1984) citaram que a maioria do crômio contido no solo ocorre como $\mathrm{Cr}^{3+}$ dentro da estrutura dos minerais e óxidos contendo $\mathrm{Cr}^{3+} \mathrm{e} \mathrm{Fe}^{3+} \cdot \mathrm{O}^{3+}$ é pouco móvel em solos. Em pH 5,5, é quase completamente precipitado, o que o torna muito estável nos solos.

Fischer et al. (1994) salientam que o $\mathrm{Cr}^{3+}$ segue as reações gerais dos metais pesados catiônicos, isto é, complexação com matéria orgânica, troca de cations na superficie de ácidos húmicos e minerais de argila e formação de hidróxidos de baixa solubilidade. A imobilização do crômio no solo devido a essas reações é considerada fundamental para impedir a entrada do elemento na cadeia alimentar. Griffin et al. (1977) verificaram que a adsorção de crômio nas argilas é altamente dependente do pH; enquanto a adsorção de $\mathrm{Cr}(\mathrm{VI})$ decresce com o incremento de $\mathrm{pH}$, a adsorção de $\mathrm{Cr}^{3+}$ aumenta nessas mesmas condições.

Os anions de $\mathrm{Cr}$ (VI) no solo competem com os demais anions em solução por sítios de troca na superficie de óxidos ou outros colóides de carga superficial positiva. A 
adsorção do íon cromato $\left(\mathrm{CrO}_{4}{ }^{2-}\right)$ ocorre de forma similar a do $\mathrm{HPO}_{4}{ }^{2-}$, ambos fortemente retidos por sítios de troca, caracterizando a adsorção química, enquanto que o dicromato $\left(\mathrm{Cr}_{2} \mathrm{O}_{7}{ }^{2 \cdot}\right)$ apresenta comportamento similar ao $\mathrm{H}_{2} \mathrm{PO}_{4}^{-}$, retidos com menor intensidade (Reisenauer, 1982). Entretanto, o Cr (VI) é muito instável no solo, sendo solúvel tanto em solos ácidos quanto alcalinos, porém principalmente nos alcalinos, nos quais sua mobilidade é maior (Bartlett \& Kimble, 1976b).

No caso da solubilidade do $\mathrm{Cr}^{3+}$, espécie predominante de crômio no solo, em comparação com outros metais, Soon \& Abboud (1993) descreveram a seguinte ordem: $\mathrm{Cd}>\mathrm{Ni}>\mathrm{Pb} \geq \mathrm{Cr}$. Bergkvist et al. (1989) classificaram os metais em termos de mobilidade no solo, com aumento na lixiviação de $\mathrm{Ca}, \mathrm{Cd}, \mathrm{Mg}, \mathrm{Mn}, \mathrm{Na}, \mathrm{Ni}, \mathrm{Zn}$ e $\mathrm{Al}$ sendo associada com o aumento da acidez, enquanto que a lixiviação de $\mathrm{Cr}, \mathrm{Cu}, \mathrm{Fe}, \mathrm{Pb}$ e Al foi associada com a solubilidade da matéria orgânica.

Dessa forma, o comportamento do crômio no solo pode ser modificado por complexos orgânicos, na medida em que os quelatos solúveis formados entre o metal e os ligantes orgânicos podem reduzir as concentrações desse metal na solução. Senesi et al. (1989) encontraram que os metais derivados da aplicação de resíduos orgânicos foram seletivamente adsorvidos nos ácidos húmicos do solo, sendo que o $\mathrm{Cu}, \mathrm{Ni}, \mathrm{Zn}, \mathrm{Fe}$ e $\mathrm{Cr}$ foram mais fortemente adsorvidos em comparação ao Mn, V, Ti e Mo.

A matéria orgânica atua também como fonte de eletrons na redução do $\operatorname{Cr}(\mathrm{VI})$ para $\mathrm{Cr}^{3+}$. Devido a essa característica, a aplicação de adubos orgânicos pode diminuir os efeitos tóxicos em solos polúdos por crômio (Kabata-Pendias \& Pendias, 1984). Essa redução é favorecida pela acidez do meio e daí ser mais lenta em solos alcalinos. Embora a redução do $\mathrm{Cr}(\mathrm{VI})$ seja comumente citada, a oxidação do $\mathrm{Cr}^{3+}$ tem sido também observada, aparentemente como um efeito da capacidade de oxidação de compostos contendo $\mathrm{Mn}$. Os óxidos de manganês são os únicos oxidantes de $\mathrm{Cr}$ que ocorrem naturalmente, sendo sua fonte o mineral birnessita (Bartlett \& James, 1979). A oxidação do crômio pelos óxidos de manganês é inibida a altos valores de $\mathrm{pH}$. Estudos 
confirmaram que a origem da inibição da oxidação do $\mathrm{Cr}^{3+}$ é a formação do precipitado $\left[\mathrm{Cr}(\mathrm{OH})_{3} \cdot \mathrm{nH}_{2} \mathrm{O}\right]$ (Fendorf et al, 1994).

Bartlett \& James (1979) realizaram um experimento para avaliar a oxidação do $\mathrm{Cr}^{3+} \mathrm{a} \mathrm{Cr}$ (VI) por óxidos de $\mathrm{Mn}$ e verificaram que ela não ocorreu em solos com baixos valores de $\mathrm{pH}$, ou seja, em condições nas quais o Mn encontrava-se, preferencialmente, na forma reduzida. Os autores verificaram que a oxidação foi menor em solos submetidos a secamento e armazenamento e que as amostras de terra secas, pulverizadas, peneiradas e armazenadas, após serem misturadas a outras amostras frescas e incubadas à capacidade de campo por 2 meses, tiveram a oxidação de $\mathrm{Cr}^{3+}$ aumentada. Do mesmo modo, as amostras de solo com baixos valores de $\mathrm{pH}$, após receberem calcário e serem incubadas à capacidade de campo, apresentaram aumento na quantidade de $\mathrm{Cr}$ oxidado.

Quando adicionado ao solo, o crômio é rapidamente imobilizado: o $\mathrm{Cr}^{3+}$ por adsorção, hidrólise e reações de quelação e o $\mathrm{Cr}(\mathrm{VI})$ por adsorção aniônica e redução a $\mathrm{Cr}^{3+}$. Entretanto, os produtos dessas reações, juntamente com outras formas nãominerais, e as pequenas quantidades de $\mathrm{Cr}(\mathrm{VI})$ observadas em solos são as principais contribuições para o crômio "disponível" do solo (Reisenauer, 1982).

No complexo matricial do solo, várias espécies podem estar presentes influenciando a adsorção do $\mathrm{Cr}^{3+}$ e, também, a oxidação por óxidos de $\mathrm{Mn}$. Ions metálicos, particularmente o $\mathrm{Al}$, inibem a oxidação do $\mathrm{Cr}^{3+}$ por óxidos de $\mathrm{Mn}$, pelo fato de serem adsorvidos por estes óxidos à medida que aumenta o $\mathrm{pH}$. Outro íon trivalente, $\mathrm{Fe}^{3+}$, é também capaz de inibir a oxidação do $\mathrm{Cr}^{3+}$ por $\mathrm{MnO}_{2}$ (Fendorf et al., 1994). Essa característica é possivelmente explicada pelo fato de o comportamento do $\mathrm{Cr}^{3+}$ assemelhar-se aos do $\mathrm{Fe}^{3+}$ e $\mathrm{Al}^{3+}$, principalmente em relação ao raio iônico e às propriedades geoquímicas (Kabata-Pendias \& Pendias, 1984).

Fendorf et al. (1994), estudando a competição de ions na oxidação do $\mathrm{Cr}^{3+}$ por $\mathrm{MnO}_{2}$, verificaram que somente o $\mathrm{Al}$ afetou a oxidação do $\mathrm{Cr}^{3+}$ a $\mathrm{pH} \geq 4$ e a $\mathrm{pH}$ 5. A presença de $\mathrm{Al}$, com 2,84 $\mu \mathrm{mol}$ de $\mathrm{Cr}^{3+}$ inicialmente presente, causou diminuição na oxidação, de 2,80 para $0,28 \mu \mathrm{mol}$ de $\mathrm{Cr}(\mathrm{VI})$. 
As condições ácido-base do meio também podem influenciar a oxidação de $\mathrm{Cr}^{3+} \mathrm{a}$ $\mathrm{Cr}$ (VI). Em soluções ácidas, o produto desta oxidação é o íon dicromato $\left(\mathrm{Cr}_{2} \mathrm{O}_{7}{ }^{2-}\right)$, enquanto que em soluções básicas, ions cromato $\left(\mathrm{CrO}_{4}{ }^{2-}\right)$ são produzidos.

O crômio adicionado ao solo é usualmente acumulado na camada superficial. Regitano (1978), estudando o movimento vertical do crômio em solos, verificou que, em condições de laboratório, nas quais o elemento foi adicionado em excesso a solos de baixo teor de matéria orgânica, todo $\mathrm{Cr}^{3+}$ e uma parte do $\mathrm{Cr}(\mathrm{VI})$ permaneceram retidos nas camadas superficiais. O crômio hexavalente restante foi totalmente lixiviado.

Grove \& Ellis (1980) sugeriram as seguintes reações para ilustrar o comportamento das espécies de crômio no solo:

I. $\mathrm{Cr}^{3+}+6 \mathrm{H}_{2} \mathrm{O} \Leftrightarrow \mathrm{Cr}\left(\mathrm{H}_{2} \mathrm{O}\right)_{6}{ }^{3+} \Leftrightarrow\left[\mathrm{Cr}(\mathrm{OH})_{\mathrm{x}}\left(\mathrm{H}_{2} \mathrm{O}\right)_{6-\mathrm{x}}\right]^{3-\mathrm{x}}+\mathrm{xH}^{+} \Leftrightarrow 1 / 2 \mathrm{Cr}_{2} \mathrm{O}_{3} \cdot \mathrm{zH}_{2} \mathrm{O}$

II. $\mathrm{Cr}_{2} \mathrm{O}_{3}+\mathrm{H}_{2} \mathrm{O} \Leftrightarrow \mathrm{H}_{2} \mathrm{CrO}_{4} \Leftrightarrow 2 \mathrm{H}^{+}+\mathrm{CrO}_{4}{ }^{2-}{ }^{6 \mathrm{H}+} \underset{{ }_{\mathrm{I}}}{ } \rightarrow \underset{\mathrm{Cr}^{3+}}{\rightarrow}+4 \mathrm{H}_{2} \mathrm{O}$

Ainda Grove \& Ellis (1980) verificaram que a adição de $\mathrm{Cr}^{3+}$ provocou diminuição do $\mathrm{pH}$ de três solos estudados, sendo que ela foi mais drástica no solo com valor $\mathrm{pH}$ inicial mais baixo. O crômio adicionado ao solo, na forma hexavalente, provocou diminuição do $\mathrm{pH}$ no início, com posterior aumento em todos os solos após 16 semanas de incubação. $\mathrm{O} \mathrm{pH}$ dos solos tratados com resíduo contendo crômio apresentou grande incremento inicial, diminuindo com o tempo de incubação.

O conhecimento das condições que afetam a oxidação do $\mathrm{Cr}^{3+}$ é importante para prever o comportamento do elemento no solo, permitindo a determinação de condições que facilitem ou retardem a formação do $\mathrm{Cr}(\mathrm{VI})$. 


\subsection{Resíduo de curtume}

O curtimento com crômio vem sendo utilizado desde o começo do século para a produção de couros leves (cromo, vaqueta, napa, entre outros) e a principal vantagem desse método reside na abreviação do tempo de curtimento, para menos de um dia, além de produzir couro com maior resistência ao calor e ao desgaste.

Atualmente, a maioria dos couros curtidos com crômio é produzida em um único banho de sulfato básico de crômio $\left[\mathrm{Cr}_{2} \mathrm{SO}_{4}(\mathrm{OH})_{2}\right]$. O couro absorve sais de crômio na proporção de 3 a 7\% do seu peso, sendo que esta operação é realizada adicionando-se sulfato básico de crômio com mínimo de 1,5\% e máximo de $5 \%$ de $\mathrm{Cr}_{2} \mathrm{O}_{3}$ (Braille \& Cavalcanti, 1979). Os resíduos gerados por esse processo são denominados de resíduos de curtume.

O descarte de resíduos de curtume em cursos d'água é prejudicial, não apenas pelos sólidos em suspensão e pela demanda biológica de oxigênio (DBO) presente, mas, principalmente, pelos seus altos teores de sulfetos e sais (Braille \& Cavalcanti, 1979). Dentre todos os resíduos produzidos pelos curtumes, o resíduo do curtimento com crômio corresponde a $6,2 \%$ do total em termos de vazão, $5,5 \%$ do total da DBO e $2,5 \%$ do total de sólidos solúveis presentes nos resíduos.

O sulfato de crômio pode ser recuperado para reutilização no curtume através da precipitação do hidróxido crômico, filtração e redissolução com $\mathrm{H}_{2} \mathrm{SO}_{4}$, porém a maior parte dos curtidores considera tal operação anti-econômica (Braille \& Cavalcanti, 1979).

O uso agrícola de resíduos de curtume é uma prática que ainda não é realizada com segurança, devido à falta de informações sobre o assunto. No entanto, grande parte dos trabalhos relacionados ao estudo desses resíduos indica que a sua aplicação pode resultar em alterações nas características químicas e biológicas do solo.

Pombo et al. (1991), estudando o descarte de resíduo de curtume em um solo Podzólico Vermelho-Amarelo, concluíram que a CTC do solo aumentou com as doses de 
lodo aplicadas, e que a adição do resíduo não apresentou prejuízos ao rendimento do azevém, nem propiciou teores tóxicos de metais no tecido das plantas.

Fortes et al. (1991), incorporando resíduo de curtume ao solo, verificaram que a quantidade de $\mathrm{CO}_{2}$ liberado e o $\mathrm{pH}$ do solo aumentaram em proporção direta às doses do resíduo aplicadas, indicando aumento da microbiota, principalmente bactérias $\mathrm{e}$ actinomicetos. Os teores elevados de crômio no resíduo não causaram toxicidade aos microrganismos do solo.

\subsection{Métodos para análise de crômio}

O conhecimento da disponibilidade de crômio em solos é interessante para se avaliar desde as pequenas quantidades presentes, o que pode levar as plantas a atender as quantidades exigidas pelos animais através da alimentação, até verificar os níveis altos e até mesmo fitotóxicos encontrados em solos poluídos por cromatos.

A estimativa do crômio hexavalente em solos tem sido feita utilizando o método colorimétrico do s-difenilcarbazida (Bartlett \& Kimble, 1979). Através desse método são medidas pequenas quantidades do $\mathrm{Cr}$ (VI) facilmente disponível. Para avaliar o $\mathrm{Cr}(\mathrm{VI})$, Bartlett \& Kimble (1979) fizeram a extração utilizando $\mathrm{KH}_{2} \mathrm{PO}_{4}$, por ser considerado o extrator mais eficiente em comparação com $\mathrm{NH}_{4} \mathrm{OAc}, \mathrm{HCl}, \mathrm{Na}_{4} \mathrm{P}_{2} \mathrm{O}_{7}, \mathrm{NaF}, \mathrm{KCl}$ e KCl$\mathrm{KHCO}_{3}$. A escolha do $\mathrm{KH}_{2} \mathrm{PO}_{4}$ foi feita em função de apresentar maior afinidade pelos sítios de troca do solo que o $\mathrm{Cr}(\mathrm{VI})$, o que faz com que o elemento torne-se disponível; o $\mathrm{KH}_{2} \mathrm{PO}_{4}$ não remove componentes orgânicos que interferem no método colorimétrico de determinação do $\mathrm{Cr}(\mathrm{VI})$; o extrator não causa diminuição do $\mathrm{pH}$, responsável pela redução do $\mathrm{Cr}(\mathrm{VI})$ durante o processo de extração. $\mathrm{Na}$ análise do teor de $\mathrm{Cr}(\mathrm{VI})$ pelo método colorimétrico do s-difenilcarbazida, o crômio hexavalente reage com a difenilcarbazida, a qual é altamente seletiva a essa forma do elemento, produzindo um 
complexo vermelho-violeta, cuja absorbância é medida espectrofotometricamente a 540 nm.

O uso do método do s-difenilcarbazida com algumas modificações em relação à forma de extração tem sido também estudado em trabalhos recentes envolvendo crômio (Vitale et al., 1994; James, 1994). Esse método se baseia na extração de crômio por digestão a quente de amostras sólidas, utilizando uma solução alcalina a pH 12, contendo $0,28 \mathrm{~mol} \mathrm{~L}^{-1}$ de $\mathrm{Na}_{2} \mathrm{CO}_{3}$ e $0,5 \mathrm{M} \mathrm{NaOH}$, responsável pela extração do $\mathrm{Cr}$ (VI). Com a presença do $\mathrm{Cr}(\mathrm{VI})$ na solução, a análise é feita adicionando-se solução de difenilcarbazida em acetona e ajustando-se a 2 o pH da solução, usando $\mathrm{H}_{2} \mathrm{SO}_{4}$. A quantificação é feita da mesma maneira que no método do s-difenilcarbazida, ou seja, através de leitura de absorbância em espectrofotômetro a $540 \mathrm{~nm}$ e relação com curva padrão previamente preparada.

Geralmente, o teor de $\mathrm{Cr}^{3+}$ é calculado pela diferença entre o teor total de $\mathrm{Cr}$ do solo e o de $\mathrm{Cr}(\mathrm{VI})$. Entretanto, em alguns casos, realiza-se a extração direta de $\mathrm{Cr}^{3+}$ do solo, embora se trate de um procedimento mais complicado, já que essa forma de crômio encontra-se, preferencialmente, adsorvida às partículas do solo.

Testando diferentes caminhos para a extração do $\mathrm{Cr}^{3+}$ do solo, Bartlett \& Kimble (1976a) verificaram que o pirofosfato $\left(\mathrm{Na}_{4} \mathrm{P}_{2} \mathrm{O}_{7}\right)$ foi o extrator mais eficiente em solos que receberam adição de $\mathrm{CrCl}_{3}$. Isso indica que o crômio extraído estava provavelmente ligado à fração orgânica do solo. Os autores também concluíram que o $\mathrm{HCl}$, por outro lado, é responsável, preferencialmente, pela extração de formas inorgânicas de $\mathrm{Cr}^{3+}$, como hidróxidos e fosfatos.

Grove \& Ellis (1980) utilizaram uma sucessão de extratores (água destilada, $\mathrm{NH}_{4} \mathrm{Cl} 1 \mathrm{~mol} \mathrm{~L}^{-1}, \mathrm{CuSO}_{4} 0,1 \mathrm{~mol} \mathrm{~L}^{-1},\left(\mathrm{NH}_{4}\right)_{2} \mathrm{C}_{2} \mathrm{O}_{4}$ e citrato-ditionito-bicarbonato) para a extração de crômio solúvel em água, trocável, ligado à fração orgânica, precipitado-amorfo e precipitado-cristalino, respectivamente. As extrações com oxalato e ditionito removeram grandes quantidades de $\mathrm{Cr}$ de todos os tratamentos, enquanto que o $\mathrm{CuSO}_{4} \mathrm{e}$ o $\mathrm{NH}_{4} \mathrm{Cl}$ não apresentaram diferenças significativas. Os autores concluíram que o 
oxalato de amônio é um extrator eficiente para crômio adicionado ao solo via lodo de esgoto, $\mathrm{CrCl}_{3}$ ou $\mathrm{Cr}_{2} \mathrm{O}_{3}$.

Abreu et al. (1995), visando a comparar métodos de análise para avaliar a disponibilidade de metais pesados em solos, concluíram que os extratores Mehlich 1, Mehlich 3 e DTPA apresentaram baixa eficiência para avaliar a disponibilidade dos elementos $\mathrm{Pb}, \mathrm{Cd}, \mathrm{Cr}$ e $\mathrm{Ni}$ em amostras de solo não contaminadas. O extrator Mehlich 3 teve maior capacidade de extração de $\mathrm{Cd}, \mathrm{Cr}$ e $\mathrm{Ni}$ em solos, seguindo-se o extrator Mehlich 1 e DTPA.

\subsection{Biodegradabilidade de resíduos}

O estudo de resíduos orgânicos e industriais para uso agrícola é conhecido há longo tempo, mas os problemas associados com o acúmulo de metais pesados no solo, em aplicações sucessivas destes resíduos, começaram a ser reconhecidos recentemente (Williams et al., 1987).

Os efeitos tóxicos dos metais pesados sobre os microrganismos do solo e nos processos mediados por eles, bem como as transformações ocorridas nos metais pela ação da microbiota do solo, têm sido estudados por Summers \& Silver (1978), Fritze et al. (1989), entre outros.

Chander et al. (1995) adicionaram lodos enriquecidos com $\mathrm{Ni}, \mathrm{Zn}, \mathrm{Cu}$ e $\mathrm{Cd}$ a vários solos e observaram que, até quatro semanas após a incubação dos resíduos nos solos, os metais presentes no lodo não influenciaram a síntese de carbono pela biomassa microbiana. Após esse período, a biomassa diminuiu, independentemente do tipo de lodo ou da dose aplicada. Possivelmente, essa queda na biomassa microbiana seja explicada pelo aumento na disponibilidade dos metais com o tempo de incubação, antes adsorvidos ao solo. Entretanto, os efeitos dos metais sobre os microrganismos podem ser 
confundidos com os efeitos de outros fatores como $\mathrm{pH}$, textura, matéria orgânica e variações sazonais na temperatura e umidade.

Geralmente, quando se adiciona carbono orgânico ao solo, seja este na forma de resíduos ou outro material orgânico, a quantidade de biomassa microbiana aumenta. Medidas da respiração do solo após a sua incubação com componentes orgânicos têm sido utilizadas, freqüentemente, para determinar se esses materiais são biodegradáveis e, com isso, a velocidade e o grau de mineralização dos mesmos (Anderson, 1982).

Benedetti et al. (1991) avaliaram, através da liberação de carbono na forma de $\mathrm{CO}_{2}$ e do incremento no teor de nitrato do solo, a mineralização de um resíduo de curtume, aplicado em quantidade equivalente a $100 \mathrm{mg} \mathrm{kg}^{-1} \mathrm{Cr}$. Os autores verificaram que, após duas semanas de incubação a $30^{\circ} \mathrm{C}, 73 \%$ do resíduo foi mineralizado, chegando a $100 \%$ de mineralização após oito semanas. No entanto, apesar de o resíduo ter se decomposto rapidamente, foram liberadas quantidades muito pequenas de crômio $[<0,5$ $\mathrm{mg} \mathrm{kg}^{-1}$ de $\mathrm{Cr}^{3+}$ e $\left.\mathrm{Cr}(\mathrm{VI})\right]$.

A medida da respiração do solo é importante em muitos estudos relacionados à aplicação de metais pesados no solo via resíduos orgânicos ou industriais. Muitas técnicas têm sido usadas para determinar a quantidade total de $\mathrm{CO}_{2}$ liberado pela respiração dos microrganismos; dentre elas destaca-se a da respirometria, cujo procedimento foi descrito por Anderson (1982), sendo a medida do $\mathrm{CO}_{2}$ liberado pelo solo feita por análise volumétrica, como descrito por Jenkinson \& Powlson (1976). 


\section{MATERIAL E MÉTODOS}

\subsection{Local do experimento}

O experimento foi conduzido em casa de vegetação/laboratório, localizados no Departamento de Tecnologia e no Laboratório de Fertilidade do Solo, da Faculdade de Ciências Agrárias e Veterinárias de Jaboticabal / UNESP, Campus de Jaboticabal, SP.

\subsection{Solo}

Os solos utilizados no experimento foram: Latossolo Roxo (LR) e Latossolo Vermelho Amarelo (LV). O critério de escolha dos solos foi baseado na representatividade dos mesmos e em função de seus teores de manganês. As amostras de Latossolo Roxo foram coletadas na Faculdade de Ciências Agrárias e Veterinárias de Jaboticabal (UNESP) e as amostras de Latossolo Vermelho Amarelo foram obtidas junto à Estação Experimental de Piracicaba do Instituto Agronômico de Campinas (IAC), na profundidade $0-20 \mathrm{~cm}$. Os solos foram secos, passados em peneira de $2 \mathrm{~mm}$ de abertura de malha e submetidos a análises granulométrica (método da pipeta) e química, segundo metodologia do IAC proposta por Camargo et al. (1986). Os resultados dessas análises são apresentados nas Tabelas 1 e 2. 
Tabela 1 - Caracterização granulométrica dos solos utilizados no experimento.

\begin{tabular}{ccccccccc}
\hline Solo & Argila & Silte & $\mathrm{AMF}^{(1)}$ & $\mathrm{AF}^{(2)}$ & $\mathrm{AM}^{(3)}$ & $\mathrm{AG}^{(4)}$ & $\mathrm{AMG}^{(5)}$ & $\mathrm{AT}^{(6)}$ \\
\hline $\mathrm{LV}$ & 430 & 190 & 70 & 180 & 70 & 30 & 30 & 380 \\
$\mathrm{LR}$ & 520 & 290 & 60 & 80 & 40 & 10 & 0 & 190 \\
\hline
\end{tabular}

${ }^{(1)} \mathrm{AMF}=$ areia muito fina; ${ }^{(2)} \mathrm{AF}=$ areia fina; $;{ }^{(3)} \mathrm{AM}=$ areia média; ${ }^{(4)} \mathrm{AG}=$ areia grossa; $;{ }^{(5)} \mathrm{AMG}=$ areia muito grossa; ${ }^{(6)} \mathrm{AT}=$ areia total

\subsection{Fontes}

As fontes de crômio utilizadas nos experimentos foram: $\mathrm{CrCl}_{3}, 6 \mathrm{H}_{2} \mathrm{O}$ (fonte de $\left.\mathrm{Cr}^{3+}\right), \mathrm{K}_{2} \mathrm{Cr}_{2} \mathrm{O}_{7}$ [fonte de $\left.\mathrm{Cr}(\mathrm{VI})\right]$ e resíduo de curtume, todos em doses correspondentes a 500 e $3000 \mathrm{~kg} \mathrm{ha}^{-1} \mathrm{Cr}\left(250\right.$ e $\left.1500 \mathrm{mg} \mathrm{kg}^{-1} \mathrm{Cr}\right)$. As doses de crômio foram escolhidas em função da quantidade máxima do elemento permitida para aplicação no solo (King, 1996).

\subsection{Resíduo de curtume}

$\mathrm{O}$ resíduo sólido procedente do curtimento mineral do couro foi obtido na Curtidora Curvita, no município de Patrocínio Paulista, SP.

$\mathrm{O}$ resíduo foi seco ao ar e moído em moinho tipo Willey. A caracterização química desse material foi feita de acordo com metodologia estabelecida por Tedesco et al. (1995) e Braille \& Cavalcanti (1979). Os resultados dessas análises são mostrados na Tabela 3. 


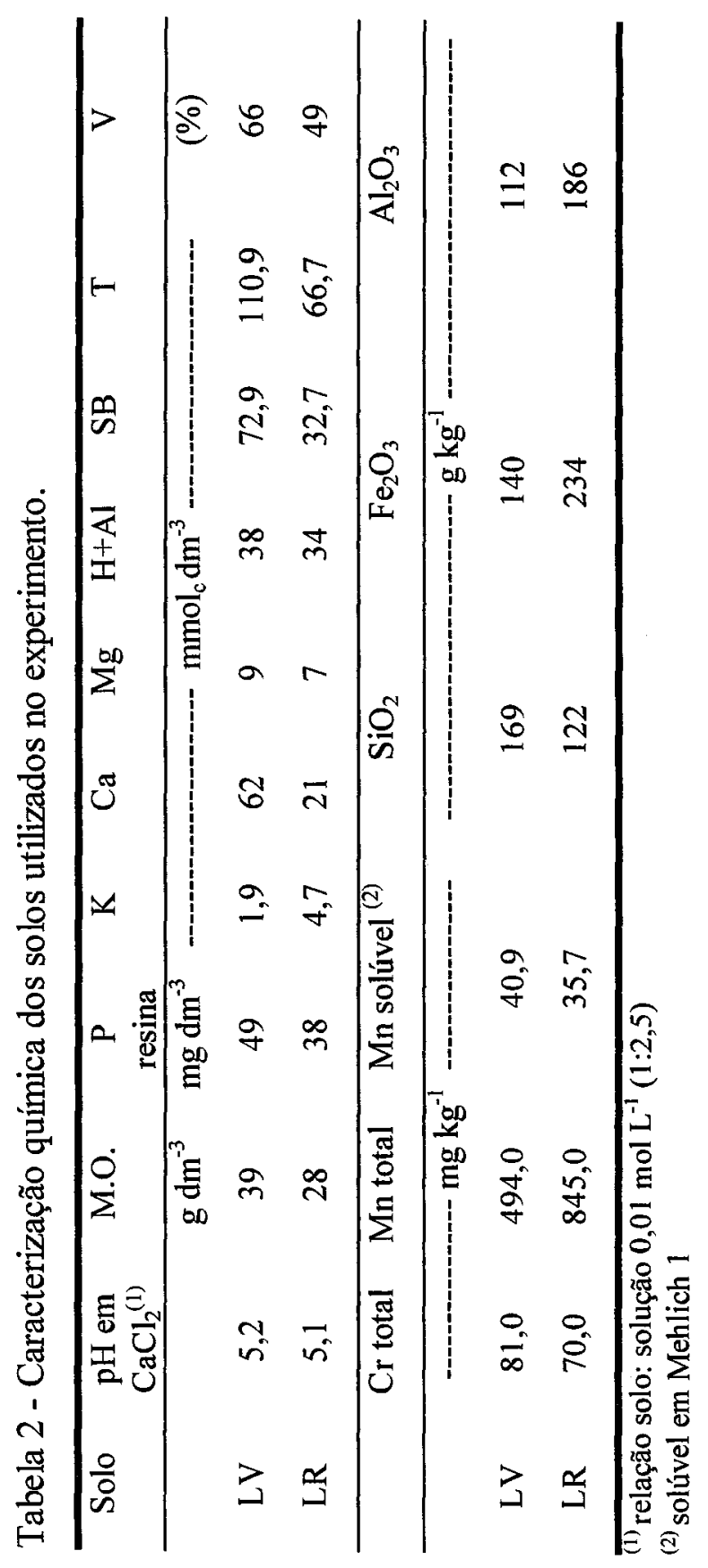


Tabela 3 - Caracterização química do resíduo de curtume utilizado no experimento ${ }^{(1)}$.

\begin{tabular}{|c|c|c|c|c|c|c|c|c|}
\hline $\mathrm{pH} \mathrm{H}_{2} \mathrm{O}$ & Umidade & $\bar{C}$ & $\overline{S T}$ & $\overline{\mathrm{SF}}$ & $\bar{N}$ & $\overline{\mathrm{K}}$ & $\mathrm{Ca}$ & $\mathrm{Mg}$ \\
\hline $7,5^{(1)}$ & 109,4 & 143,1 & 453,3 & $\begin{array}{r}-\mathrm{g} \mathrm{kg}^{-1} \\
405,0\end{array}$ & 28,6 & 0,41 & 80,0 & 3,18 \\
\hline $\mathrm{Cr}$ & $\mathrm{Fe}$ & $\mathrm{Mn}$ & $\mathrm{Na}$ & $\mathrm{Zn}$ & $\mathrm{Cu}$ & $\mathrm{Pb}$ & $\mathrm{Ni}$ & $\mathrm{Cd}$ \\
\hline 62,9 & $\begin{array}{l}8,9 \\
8,9\end{array}$ & 6,8 & 3,0 & 343,3 & 136,7 & $\begin{array}{l}\mathrm{g} \mathrm{kg}^{-1} \\
104,7\end{array}$ & 27,0 & 4,3 \\
\hline
\end{tabular}

Com base nesses dados verificou-se que a relação $\mathrm{C}: \mathrm{N}$ do resíduo de curtume utilizado é igual a 5:1. O fator de transformação do teor de carbono orgânico para matéria orgânica do resíduo é de 3,17 .

\subsection{Estudo da biodegradabilidade do resíduo}

O estudo da degradabilidade da fração orgânica do resíduo foi realizado utilizando a técnica da respirometria (Anderson, 1982). O ensaio foi conduzido em laboratório, em estufa incubadora com temperatura controlada cerca de $30^{\circ} \mathrm{C}$.

Foram colocados em frascos de vidro, dotados de tampas plásticas rosqueáveis (respirômetros), $200 \mathrm{~g}$ de terra fina seca ao ar (TFSA) e as quantidades do resíduo. de acordo com o tratamento, e água (cerca de $40 \%$ da capacidade máxima de retenção do solo). Dentro dos respirômetros foram colocados recipientes de plástico contendo $20 \mathrm{~mL}$ de solução de $\mathrm{NaOH} 1 \mathrm{~mol} \mathrm{~L}^{-1}$. $\mathrm{O} \mathrm{CO}_{2}$ liberado do solo através da decomposição de matéria orgânica foi recebido por esta solução de $\mathrm{NaOH}$, que foi substituída diariamente por outra até o $25^{\circ}$ dia. Após o $25^{\circ}$ dia, a solução de $\mathrm{NaOH}$ passou a ser substituída a cada dois dias, perfazendo o total de 61 dias de incubação. Da solução de $\mathrm{NaOH}$ com 
$\mathrm{CO}_{2}$ foi tomada alíquota de $1 \mathrm{~mL}$, que recebeu $2 \mathrm{~mL}$ de solução de cloreto de bário 0,5 mol $\mathrm{L}^{-1}$ e três gotas do indicador fenolftaleína, e foi titulada com solução padronizada de $\mathrm{HCl} 0,2 \mathrm{~mol} \mathrm{~L}^{-1}$.

Conhecendo-se o número de mmols de $\mathrm{NaOH}$, inicialmente colocados, e o número remanescente, foi obtida, por cálculo, a quantidade em $\mathrm{mg} \mathrm{CO}_{2}$ liberado ou $\mathrm{mg} \mathrm{C}$ orgânico oxidado a $\mathrm{CO}_{2}$.

$\mathrm{O}$ experimento foi conduzido no delineamento inteiramente casualizado, em esquema fatorial $4 \times 2$ ( 4 fontes e 2 solos), com 3 repetições, sendo as médias comparadas pelo Teste de Tukey $(\mathrm{P}<0,05)$. Os tratamentos (fontes) foram os seguintes: solo; solo + glicose e solo + resíduo de curtume em dose 1 e solo + resíduo de curtume em dose 2. As doses de resíduo de curtume aplicadas foram de $12,5 \mathrm{Mg} \mathrm{ha}^{-1}$ e $25 \mathrm{Mg}$ $\mathrm{ha}^{-1}$, correspondentes a $3,95 \mathrm{~g} \mathrm{~kg}^{-1}$ e 7,90 $\mathrm{g} \mathrm{kg}^{-1}$ em termos de carbono. A glicose foi utilizada como tratamento de comparação, sendo aplicada em dose equivalente de carbono à do tratamento contendo a maior dose de resíduo. Todos os tratamentos foram conduzidos em 3 repetições.

Os dados foram também aplicados a um modelo de cinética de reação de $1^{\text {a }}$ ordem, através de um programa multiparamétrico em linguagem Basic (Meites, 1976).

\subsection{Teste de extratores para análise de crômio em solos}

O experimento foi conduzido em laboratório, sendo utilizados, para isso, recipientes com $600 \mathrm{~mL}$ de capacidade. O Latossolo Roxo recebeu aplicação prévia de $\mathrm{CaCO}_{3}$, com o objetivo de elevar o índice de saturação por bases para o mais próximo possível do Latossolo Vermelho Amarelo, ou seja 66\%, no sentido de obter maior uniformidade entre os solos. As características químicas do Latossolo Roxo obtidas após calagem foram as seguintes: $\mathrm{pH} \mathrm{em} \mathrm{CaCl} 20,01 \mathrm{~mol} \mathrm{~L}^{-1}=5,4 ;$ M.O. $=26 \mathrm{~g} \mathrm{dm}^{-3} ; \mathrm{P}$ (resina) 
$=39 \mathrm{mg} \mathrm{dm}^{-3} ; \mathrm{K}=5,2 \mathrm{mmol}_{\mathrm{c}} \mathrm{dm}^{-3} ; \mathrm{Ca}=32 \mathrm{mmol}_{\mathrm{c}} \mathrm{dm}^{-3} ; \mathrm{Mg}=7 \mathrm{mmol}_{\mathrm{c}} \mathrm{dm}^{-3} ;(\mathrm{H}+\mathrm{Al})=$ $31 \mathrm{mmol}_{\mathrm{c}} \mathrm{dm}^{-3} ; \mathrm{SB}=44 \mathrm{mmol}_{\mathrm{c}} \mathrm{dm}^{-3} ; \mathrm{CTC}=75 \mathrm{mmol}_{\mathrm{c}} \mathrm{dm}^{-3} ; \mathrm{V}(\%)=59$.

Amostras de $500 \mathrm{~cm}^{3}$ de solo foram colocadas nos frascos, os quais receberam os seguintes tratamentos: soluções contendo $\mathrm{CrCl}_{3} .6 \mathrm{H}_{2} \mathrm{O}$ (fonte de $\mathrm{Cr}^{3+}$ ) e $\mathrm{K}_{2} \mathrm{Cr}_{2} \mathrm{O}_{7}$ [fonte de $\mathrm{Cr}(\mathrm{VI})]$ e resíduo de curtume em doses correspondentes a 500 e $3000 \mathrm{~kg} \mathrm{ha}^{-1}$ de $\mathrm{Cr}$ ( 250 e $1500 \mathrm{mg} \mathrm{kg}^{-1} \mathrm{Cr}$ ). A quantidade de água adicionada foi correspondente a cerca de $60 \%$ da capacidade máxima de retenção do solo.

Após 60 dias de incubação do solos com crômio, foi retirada uma amostra de solo de cada recipiente, que foi analisada úmida para teor de $\mathrm{Cr}(\mathrm{VI})$, de acordo com o método proposto por Bartlett \& James (1979). As demais análises foram feitas com o solo seco ao ar, destorroado e passado em peneira com $2 \mathrm{~mm}$ de abertura de malha. Essas análises contemplaram: $\mathrm{Cr}$ solúvel, removido pelos extratores Mehlich 1 (Nelson et al., 1953), Mehlich 3 (Mehlich, 1984) e $\mathrm{HCl} 0,1 \mathrm{~mol} \mathrm{~L}^{-1}$; teor de matéria orgânica e valor pH (Raij et al., 1987).

O experimento foi conduzido no delineamento inteiramente casualizado, em esquema fatorial $7 \times 2$ ( 7 fontes e 2 solos), com 3 repetições, sendo as médias comparadas pelo Teste de Tukey $(\mathrm{P}<0,05)$. As fontes consideradas foram as seguintes: testemunha, $\mathrm{CrCl}_{3} .6 \mathrm{H}_{2} \mathrm{O}$ dose $1 ; \mathrm{CrCl}_{3} .6 \mathrm{H}_{2} \mathrm{O}$ dose $2 ; \mathrm{K}_{2} \mathrm{Cr}_{2} \mathrm{O}_{7}$ dose $1 ; \mathrm{K}_{2} \mathrm{Cr}_{2} \mathrm{O}_{7}$ dose 2; resíduo de curtume dose 1 e resíduo de curtume dose 2.

Foram feitas correlações entre os resultados da extração com as soluções Mehlich 1, Mehlich 3 e $\mathrm{HCl} 0,1 \mathrm{~mol} \mathrm{~L}^{-1}$. Convém salientar que não foram feitas correlações entre os resultados da extração de crômio com solução de $\mathrm{KH}_{2} \mathrm{PO}_{4}$ e os demais, por tratar-se de um extrator de $\operatorname{Cr}(\mathrm{VI})$, forma que, possivelmente, não representa todo o crômio disponível do solo (Reisenauer, 1982). 


\subsubsection{Determinação do crômio hexavalente}

O crômio hexavalente do solo ou crômio facilmente disponível foi analisado segundo metodologia proposta por Bartlett \& James (1979).

- Reagentes e soluções:

solução de $\mathrm{KH}_{2} \mathrm{PO}_{4} \quad 0,01 \mathrm{~mol} \mathrm{~L} \mathrm{~L}^{-1}$ : dissolveu-se $1,36 \mathrm{~g}$ de $\mathrm{KH}_{2} \mathrm{PO}_{4}$ p.a. em água desionizada. Completou-se o volume para $1 \mathrm{~L}$.

reagente difenilcarbazida: dissolveu-se $0,4 \mathrm{~g}$ de s-difenilcarbazida em $100 \mathrm{~mL}$ de etanol 95\%. Juntou-se essa solução com $120 \mathrm{~mL}$ de $\mathrm{H}_{3} \mathrm{PO}_{4} 85 \%$ diluído em $400 \mathrm{~mL}$ de água desionizada.

- Procedimento: pesados 3,0 g de solo úmido que misturados com $25 \mathrm{~mL}$ de solução de $\mathrm{KH}_{2} \mathrm{PO}_{4} 0,01 \mathrm{~mol} \mathrm{~L}^{-1}$ em um tubo de centrífuga durante 5 minutos, foram centrifugados. Adicionou-se $1 \mathrm{~mL}$ de reagente difenilcarbazida a $8 \mathrm{~mL}$ de extrato, que, após serem misturados foi determinada a transmitância a $540 \mathrm{~nm}$ após 20 minutos, secando-se uma amostra separada de solo para expressar os resultados na base seca.

\subsection{Movimentação de crômio em colunas de solo}

O experimento foi conduzido em casa de vegetação, em colunas de solo preparadas com o auxílio de 9 anéis de tubo de PVC com $5 \mathrm{~cm}$ de diâmetro interno e 5 $\mathrm{cm}$ de altura, totalizando $45 \mathrm{~cm}$ de altura, dos quais foram utilizados $40 \mathrm{~cm}$ (Figura 1). As colunas receberam a mesma quantidade de solo, ou seja, $900 \mathrm{~g}$. A aplicação dos sais contendo crômio e do resíduo de curtume foi feita por incorporação na camada $0-10 \mathrm{~cm}$. $\mathrm{O}$ tratamento testemunha foi constituído apenas pelas amostras de solo.

As doses dos sais de crômio, bem como do resíduo de curtume, foram equivalentes a 500 e $3000 \mathrm{~kg} \mathrm{ha}^{-1}$ de $\mathrm{Cr}$, o que corresponde a 250 e $1500 \mathrm{mg} \mathrm{kg}^{-1} \mathrm{Cr}$, 
respectivamente. As colunas de solo receberam água desionizada de maneira a manter cerca de $60 \%$ da capacidade máxima de retenção do solo.

Aos 60 dias após a instalação do experimento foi adicionada água desionizada às colunas, de forma a promover lixiviação. O lixiviado foi coletado em recipientes com 250 $\mathrm{mL}$ de capacidade e pesado para avaliação da quantidade de lixiviado coletado. No lixiviado foi feita a análise dos teores totais de $\mathrm{Cr}, \mathrm{Ca}$ e $\mathrm{Mg}$ presentes. Foram escolhidos para análise no lixiviado os cations $\mathrm{Ca}$ e do $\mathrm{Mg}$ por estarem presentes em grande quantidade nos solos e no resíduo estudados e, também, pela possibilidade de remoção dos mesmos do solo pela aplicação de crômio.

O solo foi removido das colunas, tomando-se o cuidado para que as camadas 0-20 e 20-40 $\mathrm{cm}$ fossem amostradas separadamente. Amostras de solo foram imediatamente congeladas para a realização das análises de $\mathrm{Cr}$ (VI). O restante foi seco ao ar, passado em peneira com $2 \mathrm{~mm}$ de abertura de malha e armazenado para se proceder às demais análises químicas. Estas análises foram as seguintes: $\mathrm{Cr}$ total por digestão perclórico-fluorídrica (Camargo et al., 1986); Cr(VI) (Bartlett \& James, 1979); teor de matéria orgânica e valor pH (Raij et al., 1987).

O experimento foi conduzido em parcelas subdivididas, com 14 tratamentos (formando um fatorial $7 \times 2$, ou seja 7 fontes e 2 solos) e 2 subtratamentos (profundidades), com 3 repetições no delineamento inteiramente casualizado. As médias foram comparadas pelo Teste de Tukey $(\mathrm{P}<0,05)$. As fontes consideradas foram as seguintes: testemunha, $\mathrm{CrCl}_{3} .6 \mathrm{H}_{2} \mathrm{O}$ dose $1 ; \mathrm{CrCl}_{3} .6 \mathrm{H}_{2} \mathrm{O}$ dose $2 ; \mathrm{K}_{2} \mathrm{Cr}_{2} \mathrm{O}_{7}$ dose $1 ; \mathrm{K}_{2} \mathrm{Cr}_{2} \mathrm{O}_{7}$ dose 2 ; resíduo de curtume dose 1 e resíduo de curtume dose 2 .

\subsubsection{Determinação do crômio total}

A metodologia utilizada para análise de crômio total no solo foi descrita por (Camargo et al., 1986). 
- Reagentes e soluções:

Ácido perclórico concentrado p.a.

Ácido fluorídrico p.a.

Solução de ácido clorídrico $3 \mathrm{~mol} \mathrm{~L}^{-1}$ : diluiu-se $250 \mathrm{~mL}$ de $\mathrm{HCl}$ concentrado a $1 \mathrm{~L}$ com água desionizada.

- Procedimento: foi colocado 0,5 $\mathrm{g}$ de terra finamente pulverizada em cadinho de teflon e, em seguida, umedecido com três gotas de água desionizada. Adicionou-se $1 \mathrm{~mL}$ de ácido perclórico e deixado durante a noite a frio para permitir o início do ataque da matéria orgânica. Foram adicionados $5 \mathrm{~mL}$ de HF, aquecidos em banho de areia, cobrindo 3/4 da boca do cadinho com tampa de teflon. Quando apareceram os fumos brancos do ácido perclórico, retirou-se a tampa e levou-se o extrato ácido até próximo da secura, caso o extrato estivesse límpido. Caso contrário, o tratamento foi repetido. Em seguida, resfriou-se, adicionou-se $5 \mathrm{~mL}$ de $\mathrm{HCl} 3 \mathrm{~mol} \mathrm{~L}^{-1}$ e esquentou-se até dissolução do resíduo. $\mathrm{O}$ ataque perclórico-fluorídrico foi repetido até que o resíduo fosse totalmente dissolvido. Transferiu-se o extrato ácido para balão volumétrico de $50 \mathrm{~mL}$ e completou-se o volume com água desionizada. A leitura foi feita em espectrofotômetro de absorção atômica.

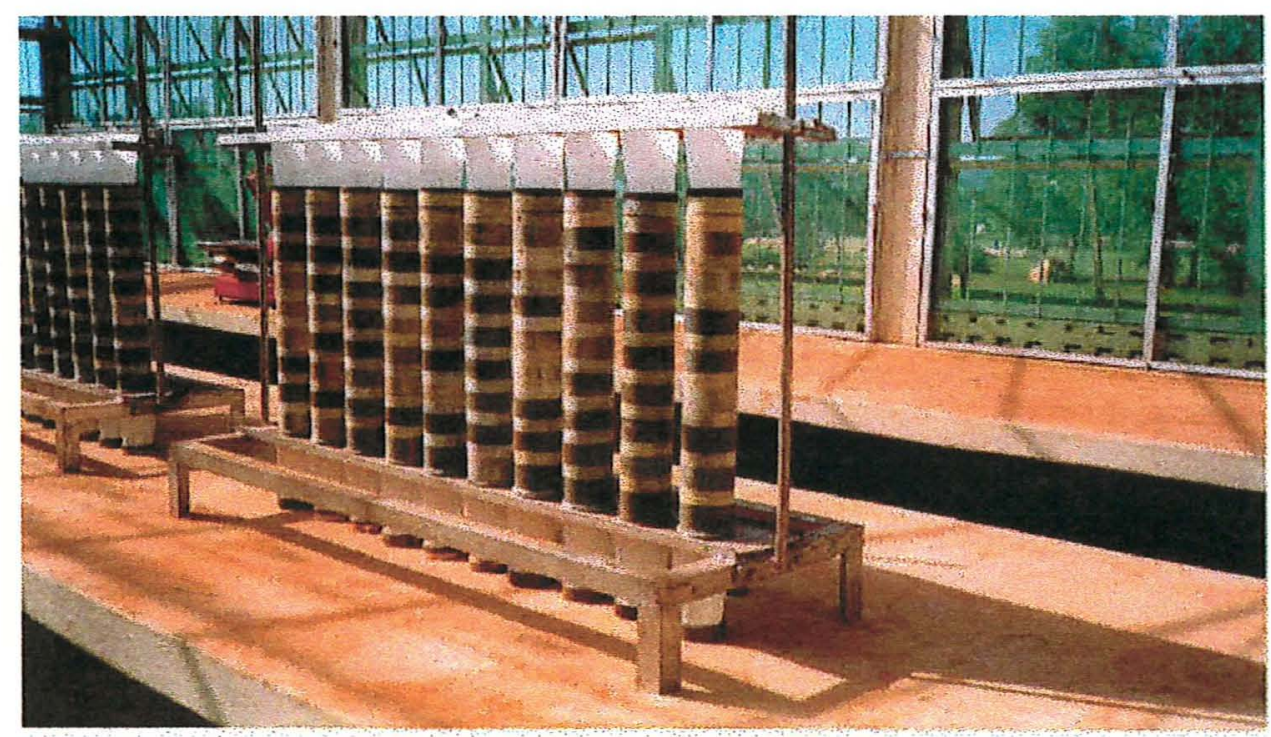

Figura 1 - Aspecto das colunas de solo no momento da lixiviação. 


\section{RESULTADOS E DISCUSSÃO}

\subsection{Estudo da biodegradabilidade do resíduo}

$\mathrm{Na}$ Tabela 4 são apresentados os resultados obtidos no ensaio de biodegradabilidade. Os dados dão indicativo da quantidade de carbono liberada durante o periodo de incubação do resíduo de curtume e da glicose com os solos, bem como a porcentagem de degradação dos mesmos. A constante de velocidade para degradação desse resíduo e da glicose, assim como a correspondente meia-vida calculada aparecem na Tabela 5.

Tábela 4 - Degradabilidade do resíduo de curtume aplicado aos solos após 61 dias de incubação.

\section{CARBONO}

\begin{tabular}{|c|c|c|c|c|c|c|}
\hline \multirow[t]{2}{*}{ Tratamentos } & \multicolumn{3}{|c|}{ LV } & \multicolumn{3}{|c|}{ LR } \\
\hline & quantidade & liberado & degradado & quantidade & liberado & degradado \\
\hline & g k & -........ & $\%$ & - $\mathrm{g} \mathrm{kg}^{-1}$ & --------- & $\%$ \\
\hline solo & 21,38 & 1,62 & $7,58 \mathrm{Ac}^{(1)}$ & 15,01 & 0,63 & $4,20 \mathrm{Bd}$ \\
\hline solo + resíduo 1 & 25,33 & 4,14 & $16,34 \mathrm{Bb}$ & 18,96 & 5,70 & $30,06 \mathrm{Ab}$ \\
\hline solo + resíduo 2 & 29,28 & 4,36 & $14,89 \mathrm{Bb}$ & 22,91 & 5,70 & $24,88 \mathrm{Ac}$ \\
\hline solo + glicose & 29,28 & 11,50 & $39,28 \mathrm{Ba}$ & 22,91 & 9,70 & $42,34 \mathrm{Aa}$ \\
\hline
\end{tabular}

${ }^{(1)}$ Médias seguidas de mesma letra maiúscula não diferem entre si na linha e médias seguidas de mesma letra minúscula não diferem entre si na coluna pelo Teste de Tukey $(\mathrm{P}<0,05)$.

resíduo $1=$ dose $12,5 \mathrm{Mg} \mathrm{ha}^{-1}$; resíduo $2=$ dose $25,0 \mathrm{Mg} \mathrm{ha}^{-1}$ 
Considerando os resultados da Tabela 4, foi possível constatar que, após 61 dias de incubação, parte da matéria orgânica do solo, juntamente com o material orgânico adicionado, foi mineralizada. Os solos que receberam material orgânico apresentaram aumento significativo na degradação do material orgânico aplicado em relação à testemunha. A glicose foi mais degradada em comparação ao resíduo de curtume, justamente por ser mais facilmente decomponível. Com relação ao resíduo de curtume, houve diferença significativa na quantidade de carbono liberado em função das doses aplicadas somente para o LR. À medida que se aumentou a dose de resíduo aplicada, houve menor degradação do material orgânico, ao contrário dos dados obtidos por Fortes et al. (1991), que observaram que a quantidade de $\mathrm{CO}_{2}$ liberado aumentou em função das doses de resíduo de curtume aplicadas. A diminuição da porcentagem de degradação em função das doses aplicadas pode ter ocorrido pela falta de $\mathrm{N}$ no meio, em relação ao $\mathrm{C}$ adicionado. A degradação do material adicionado, independentemente da fonte aplicada (exceto para a testemunha), foi maior no $L R$, atingindo valores superiores aos encontrados para o LV. Isso ocorreu, provavelmente, pelo maior estímulo à atividade dos microrganismos quando da aplicação do material orgânico ter ocorrido no LR, devido ao seu menor teor original de matéria orgânica.

Tabela 5 - Velocidade de degradação do resíduo de curtume e da glicose aplicados aos solos.

\begin{tabular}{lcccccc}
\hline Tratamentos & \multicolumn{3}{c}{ LV } & \multicolumn{3}{c}{ LR } \\
\hline & Carbono & $\mathrm{K}$ & Meia-vida & Carbono & $\mathrm{K}$ & Meia-vida \\
\cline { 2 - 7 } & $\mathrm{g} \mathrm{kg}^{-1}$ & $\operatorname{dias}^{-1}$ & dias & $\mathrm{g} \mathrm{kg}^{-1}$ & dias $^{-1}$ & dias \\
solo & 21,38 & 0,0344 & 20,14 & 15,01 & 0,0048 & 144,4 \\
solo + resíduo 1 & 25,33 & 0,0706 & 9,82 & 18,96 & 0,0675 & 10,27 \\
solo + resíduo 2 & 29,28 & 0,0732 & 9,47 & 22,91 & 0,0626 & 11,07 \\
solo + glicose & 29,28 & 0,0817 & 8,48 & 22,91 & 0,0390 & 17,77 \\
\hline
\end{tabular}

(1) Calculada pela expressão: $\ln 2 / \mathrm{K}$, onde $\mathrm{K}=$ constante de velocidade de $1^{\mathrm{a}}$ ordem resíduo $1=\operatorname{dose} 12,5 \mathrm{Mg} \mathrm{ha}^{-1}$; resíduo $2=\operatorname{dose} 25 \mathrm{Mg} \mathrm{ha}^{-1}$ 
Em relação à meia-vida, pode-se afirmar que o resíduo de curtume utilizado teve degradação semelhante à glicose no LV. A glicose teve uma degradação um pouco mais lenta que o resíduo de curtume no LR, provavelmente devido à falta de $\mathrm{N}$ no meio, acarretando numa lag-fase maior.

A evolução da quantidade de carbono liberado acumulado no período de incubação do resíduo e da glicose aos solos estudados encontram-se nas Figuras 2 e 3.

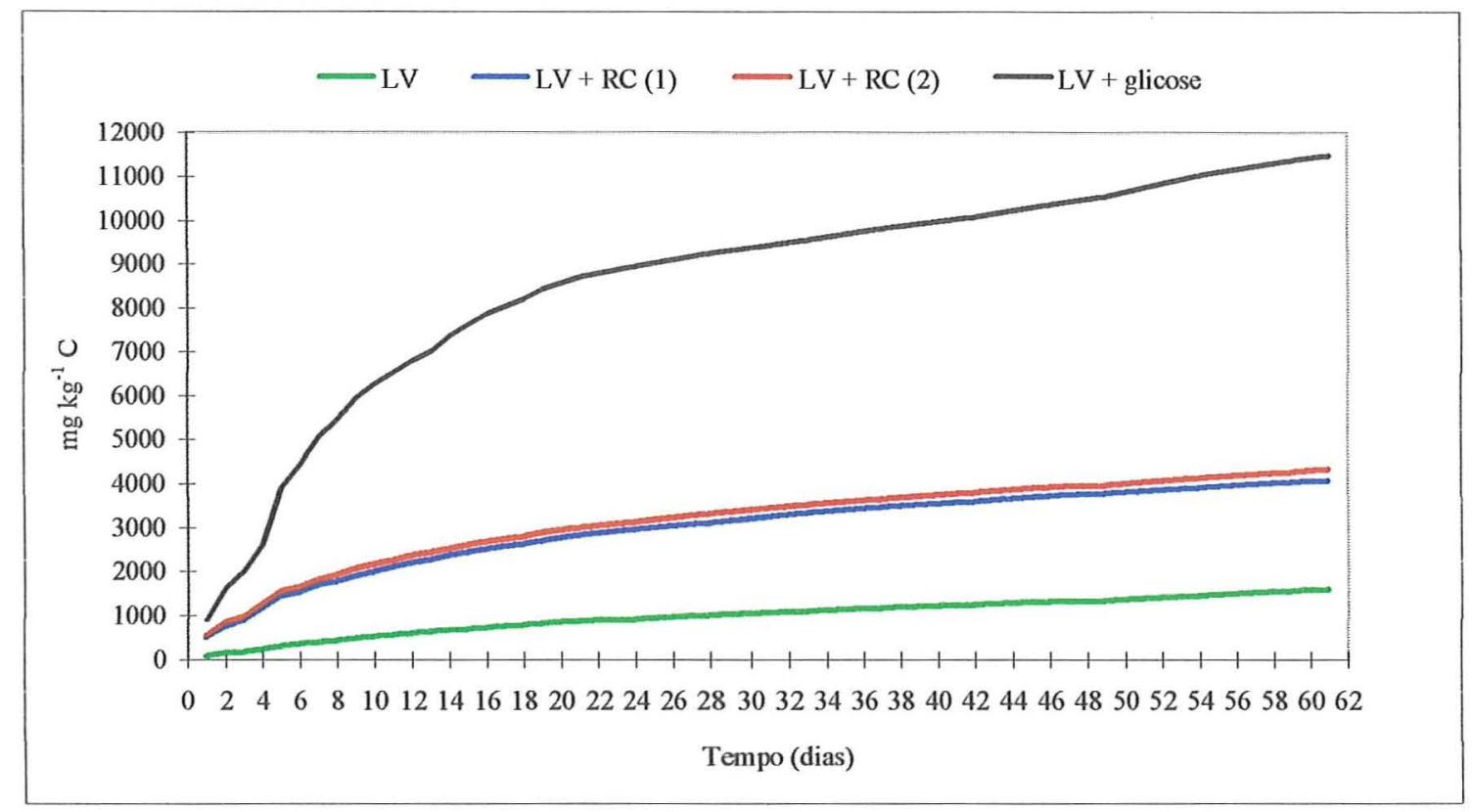

Figura 2 - Carbono liberado acumulado pela degradação do resíduo e da glicose aplicados ao Latossolo Vermelho Amarelo.

$\mathrm{RC}(1)=$ resíduo de curtume $\left(12,5 \mathrm{Mg} \mathrm{ha}^{-1}\right) ; \mathrm{RC}(2)=$ resíduo de curtume $\left(25 \mathrm{Mg} \mathrm{ha}^{-1}\right)$

Pelo exame dessas Figuras observa-se que houve maior liberação de $\mathrm{CO}_{2}$, como conseqüência da maior mineralização nos respirômetros que receberam glicose como tratamento. O resíduo de curtume, embora tenha apresentado quantidades de $\mathrm{C}$ liberadas inferiores às observadas para a glicose, não parece ter afetado os microrganismos do solo de maneira negativa. Essa constatação foi também relatada por Fortes et al. (1991). 


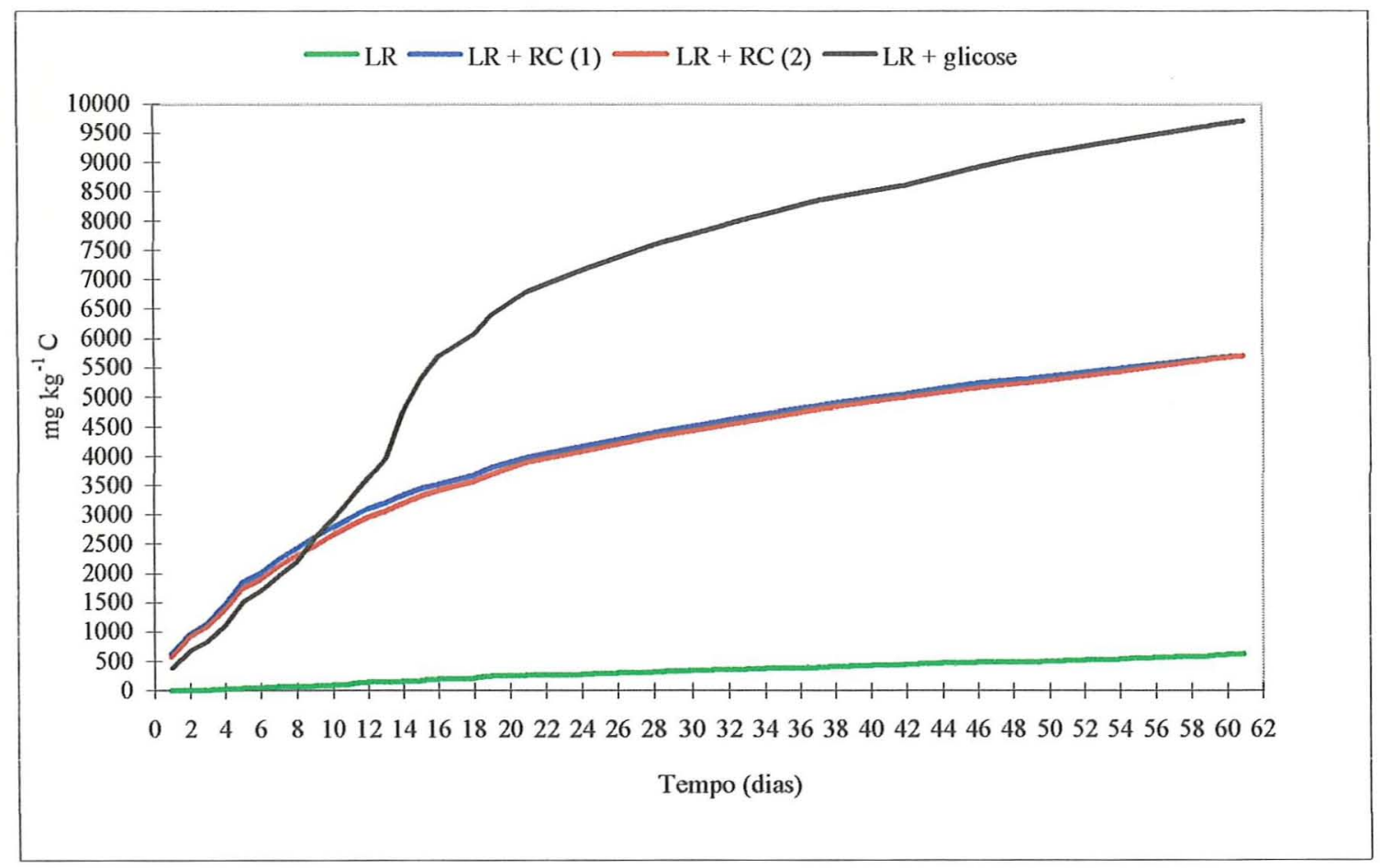

Figura 3 - Carbono liberado acumulado pela degradação do resíduo e da glicose aplicados ao Latossolo Roxo.

$\mathrm{RC}(1)$ = resíduo de curtume $\left(12,5 \mathrm{Mg} \mathrm{ha}^{-1}\right) ; \mathrm{RC}(2)=$ resíduo de curtume $\left(25 \mathrm{Mg} \mathrm{ha}^{-1}\right)$

Os resultados referentes à quantidade acumulada de $\mathrm{C}$ degradada nos solos, medida e calculada, usando-se um modelo de cinética de reação de $1^{\text {a }}$ ordem, são mostrados nas Figuras 4 e 5 . 

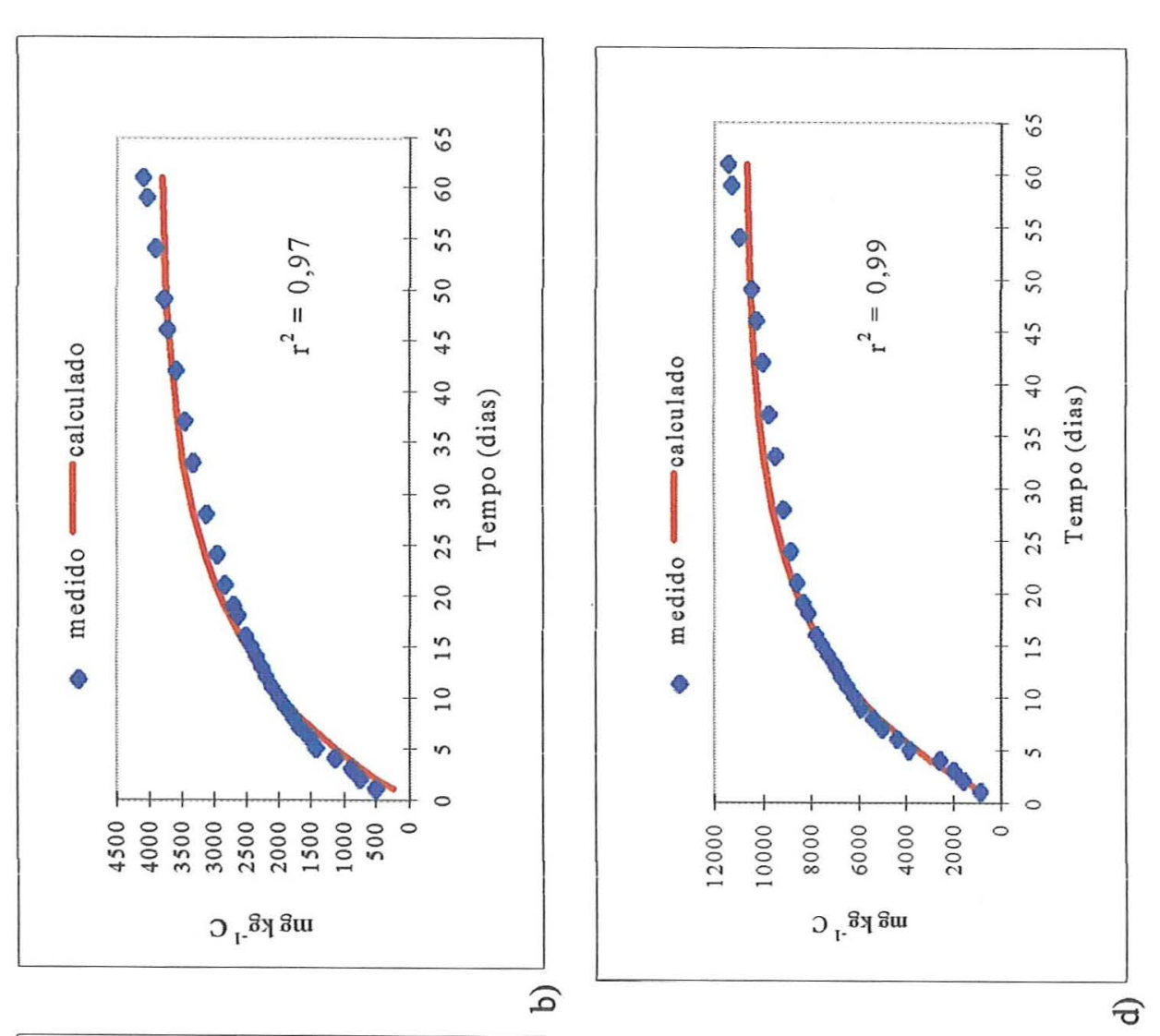

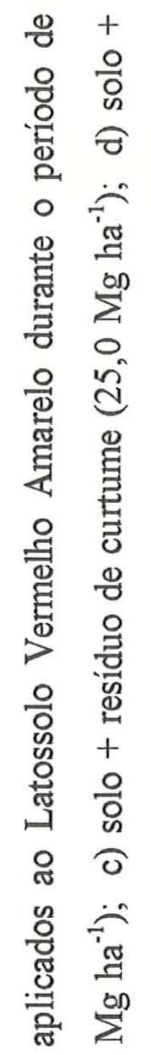
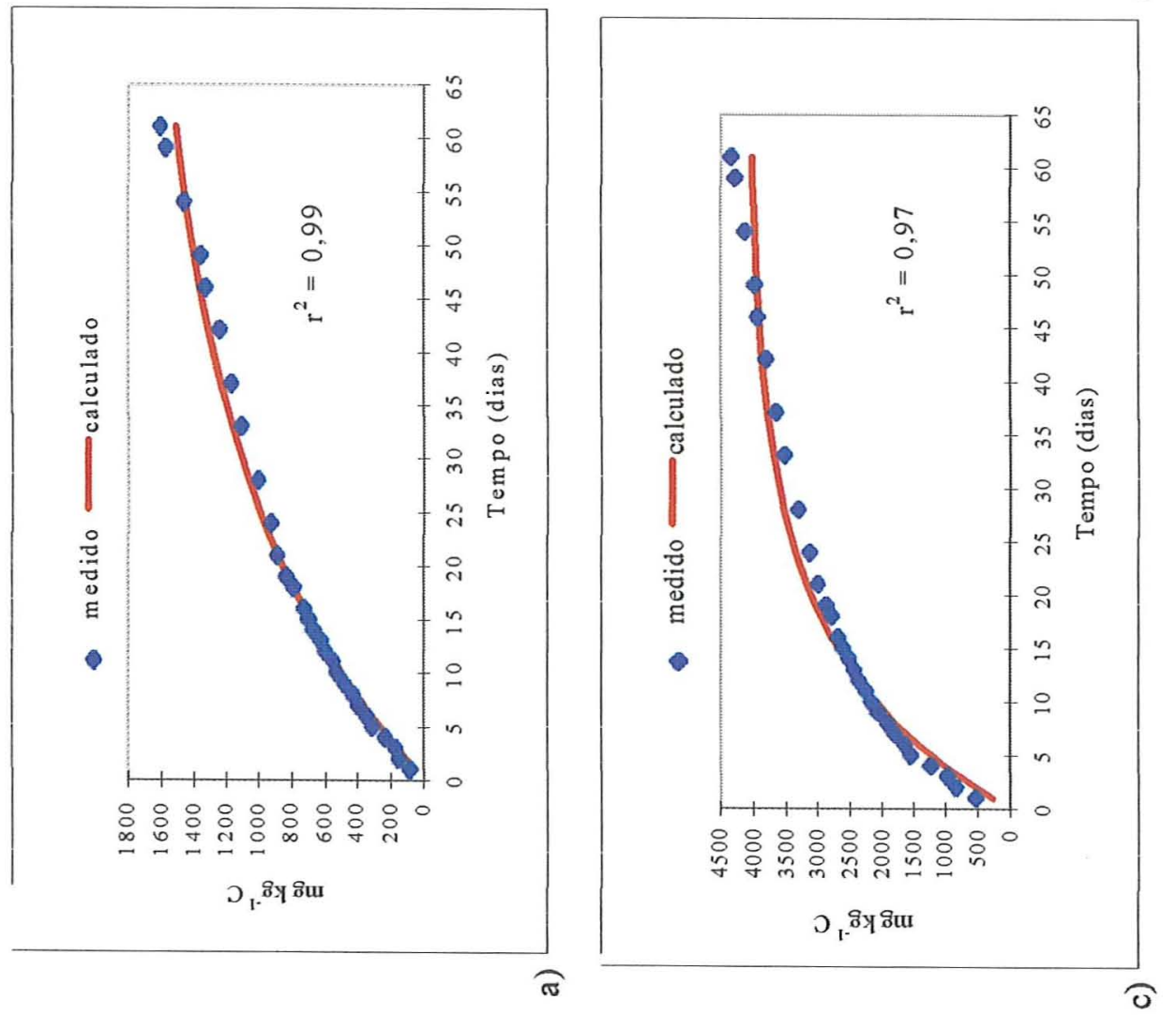

ญ ก

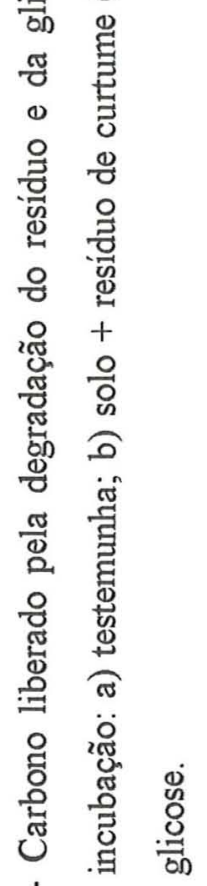



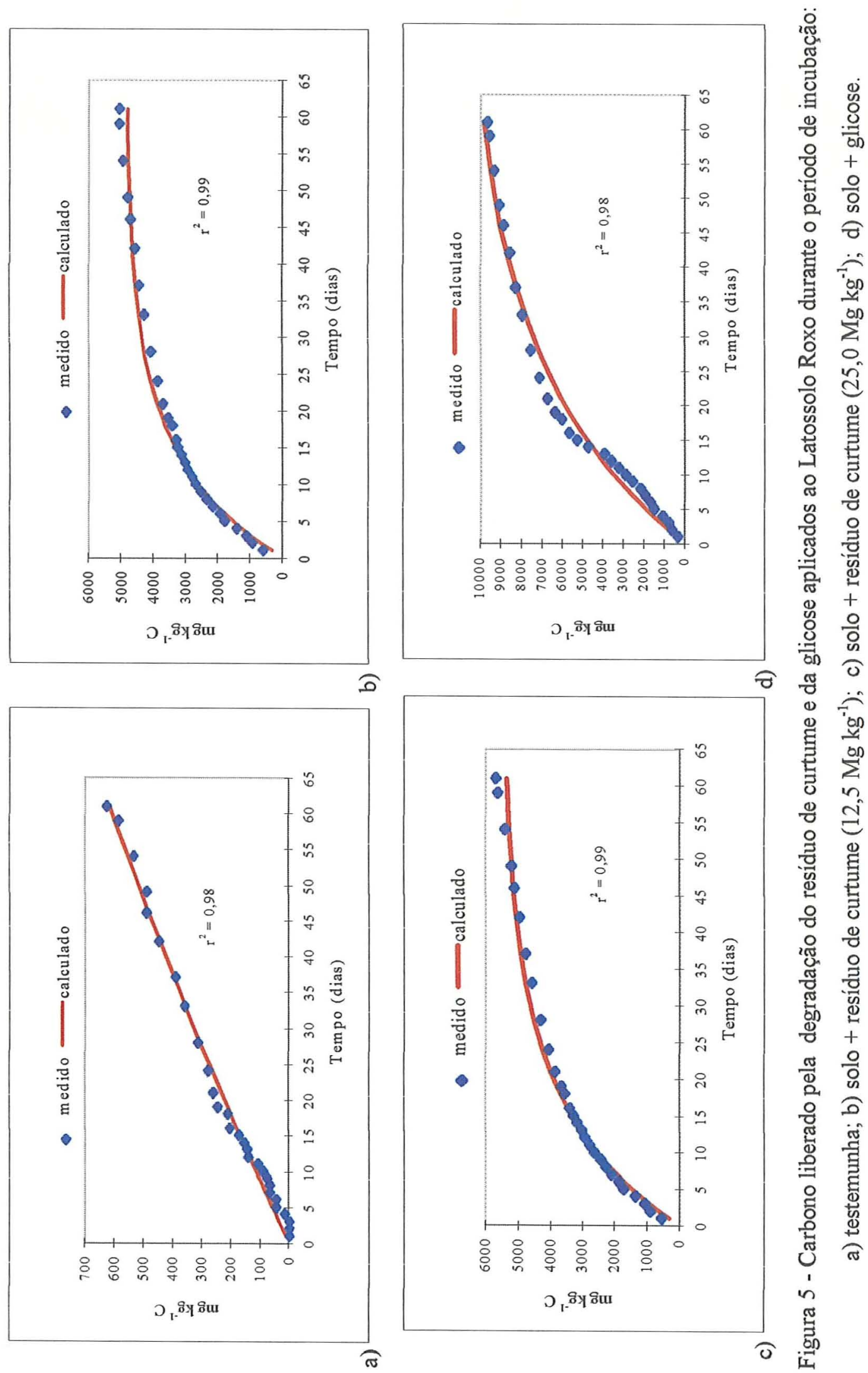
Pelos altos coeficientes de determinação obtidos, pode-se constatar que o material orgânico adicionado aos solos foi degradado de maneira muito próxima à esperada, obedecendo a um modelo de cinética de reação de $1^{\text {a }}$ ordem.

A partir dos resultados do estudo de velocidade de degradação do resíduo de curtume constatou-se que, num tempo de incubação de 61 dias, houve degradação de seu material orgânico, o que deve ter proporcionado a liberação de Cr para o meio. Dessa forma, esse tempo de incubação foi adotado para os estudos de movimentação de $\mathrm{Cr}$ e teste de extratores para o elemento, por ser considerado suficiente para a mineralização do resíduo, com conseqüente liberação do metal no solo.

\subsection{Teste de extratores para análise de crômio em solos}

Os dados referentes ao teor de crômio extraído após o período de incubação, considerando os dois solos, são apresentados nas Tabelas 6 e 7. Observa-se que, para todos os extratores, a maior quantidade de crômio foi extraída dos solos que receberam o elemento na forma hexavalente $\left(\mathrm{K}_{2} \mathrm{Cr}_{2} \mathrm{O}_{7}\right.$, dose 2$)$, o que pode ser explicado pela maior solubilidade do crômio na forma de $\mathrm{Cr}(\mathrm{VI})$ em relação ao $\mathrm{Cr}^{3+}$, cuja tendência é adsorverse às partículas do solo, como matéria orgânica, óxidos de ferro e alumínio (KabataPendias \& Pendias, 1984).

A extração de crômio com solução de $\mathrm{KH}_{2} \mathrm{PO}_{4}$ foi eficiente apenas para os tratamentos que receberam $\mathrm{Cr}(\mathrm{VI})$. Entretanto, o método é bastante sensivel, sendo indicado para os casos de contaminação do solo por cromatos e demais fontes de crômio hexavalente. Os demais extratores comportaram-se de maneira semelhante, apresentando valores de coeficiente de correlação iguais a $0,99 \mathrm{em}$ todos os casos. Pode-se dizer que, na maioria dos casos, a extração de crômio foi maior no LV (Tabela 7). 
Tabela 6 - Crômio solúvel extraído em amostras de solo por $\mathrm{HCl} 0,1 \mathrm{~mol} \mathrm{~L}^{-1}$, Mehlich 1, Mehlich 3 e $\mathrm{KH}_{2} \mathrm{PO}_{4}$ após o período de incubação.

\begin{tabular}{|c|c|c|c|c|c|}
\hline \multicolumn{2}{|c|}{ Cr adicionado } & \multicolumn{4}{|c|}{ CRÔMIO SOLÚVEL } \\
\hline Fonte & Dose & $\mathrm{HCl} 0,1 \mathrm{~mol} \mathrm{~L}^{-1}$ & Mehlich 1 & Mehlich 3 & $\mathrm{KH}_{2} \mathrm{PO}_{4}$ \\
\hline & $\mathrm{mg} \mathrm{kg}^{-1}$ & - & $\mathrm{mg} \mathrm{dm}^{-3}$ & (2) & $\mathrm{mg} \mathrm{kg}^{-1}$ \\
\hline & 0 & $0,67 \mathrm{Ab}^{(1)}$ & $0,20 \mathrm{Ad}$ & $0,17 \mathrm{Ac}$ & $0,43 \mathrm{Ac}$ \\
\hline $\mathrm{Cr}^{3+}$ & 250 & $7,87 \mathrm{Ab}$ & 18,07 Acd & $14,17 \mathrm{Ac}$ & $1,52 \mathrm{Ac}$ \\
\hline $\mathrm{Cr}^{3+}$ & 1500 & $33,33 \mathrm{Bb}$ & $111,73 \mathrm{Ab}$ & $124,33 \mathrm{Ab}$ & $0,99 \mathrm{Cc}$ \\
\hline $\mathrm{Cr}(\mathrm{VI})$ & 250 & $9,60 \mathrm{Bb}$ & $28,00 \mathrm{Bcd}$ & $33,64 \mathrm{Bc}$ & $85,63 \mathrm{Ab}$ \\
\hline $\mathrm{Cr}(\mathrm{VI})$ & 1500 & $260,00 \mathrm{Da}$ & $469,33 \mathrm{Ca}$ & $716,67 \mathrm{Aa}$ & $632,57 \mathrm{Ba}$ \\
\hline Cr-resíduo & 250 & $4,20 \mathrm{Ab}$ & $11,20 \mathrm{Ad}$ & $3,17 \mathrm{Ac}$ & $0,76 \mathrm{Ac}$ \\
\hline Cr-resíduo & 1500 & $33,87 \mathrm{Ab}$ & $47,93 \mathrm{Ac}$ & $18,67 \mathrm{ABc}$ & $0,47 \mathrm{Bc}$ \\
\hline
\end{tabular}

$\mathrm{CV}(\%)=22,10$

(1) Médias seguidas de mesma letra maiúscula não diferem na linha e médias seguidas de mesma letra minúscula não diferem na coluna pelo Teste de Tukey $(\mathrm{P}<0,05)$.

Tabela 7 - Crômio solúvel extraído em amostras de solo após o período de incubação.

\begin{tabular}{|c|c|c|c|c|c|}
\hline \multicolumn{2}{|c|}{$\mathrm{Cr}$ adicionado } & \multicolumn{4}{|c|}{ CRÔMIO SOLÚVEL } \\
\hline \multirow[t]{3}{*}{ Fonte } & Dose & $\mathrm{LV}$ & & LR & \\
\hline & $\mathrm{mg} \mathrm{kg}^{-1}$ & - & - & - & -1--- \\
\hline & 0 & 0,35 & Ad & $0,09^{(1)}$ & $\mathrm{Ac}$ \\
\hline $\mathrm{Cr}^{3+}$ & 250 & 14,60 & Acd & 6,21 & Ac \\
\hline $\mathrm{Cr}^{3+}$ & 1500 & 92,92 & $\mathrm{Ab}$ & 42,27 & $\mathrm{Bb}$ \\
\hline $\mathrm{Cr}(\mathrm{VI})$ & 250 & 67,20 & $\mathrm{Ab}$ & 11,24 & $\mathrm{Bc}$ \\
\hline $\mathrm{Cr}(\mathrm{VI})$ & 1500 & 740,03 & $\mathrm{Aa}$ & 299,26 & $\mathrm{Ba}$ \\
\hline Cr-residuo & 250 & 5,64 & Acd & 4,03 & Ac \\
\hline Cr-resíduo & 1500 & 26,79 & Ac & 23,68 & $\mathrm{Abc}$ \\
\hline
\end{tabular}

(1) Médias seguidas de mesma letra maiúscula não diferem na linha e médias seguidas de mesma letra minúscula não diferem na coluna pelo Teste de Tukey $(\mathrm{P}<0,05)$. 
Apesar de o extrator $\mathrm{KH}_{2} \mathrm{PO}_{4}$ não ter apresentado a mesma eficiência dos demais na extração de crômio solúvel dos solos, fez-se a opção de adotá-lo na etapa seguinte, por apresentar bons resultados na remoção de $\mathrm{Cr}(\mathrm{VI})$ presente no solo, além de ser o extrator indicado para estudos com $\mathrm{Cr}$ hexavalente (Bartlett \& Kimble, 1976a, b).

Os dados referentes ao conteúdo de matéria orgânica e valores de $\mathrm{pH}$ dos solos após 60 dias de incubação com os tratamentos, encontram-se na Tabela 8.

Constata-se que não houve modificações significativas em relação à testemunha no conteúdo de matéria orgânica devido à aplicação de crômio aos solos, como era esperado. Com relação ao teor de matéria orgânica original dos solos, nota-se que o mesmo permaneceu constante apenas nos solos que receberam resíduo de curtume (dose 2) e sais de crômio (dose 2), nesse último caso apenas para o LV.

Tabela 8 - Teores de matéria orgânica e valores de $\mathrm{pH}$ dos solos após o período de incubação.

\begin{tabular}{|c|c|c|c|c|c|}
\hline \multicolumn{2}{|c|}{$\mathrm{Cr}$ adicionado } & \multicolumn{2}{|c|}{ MATÉRIA ORGÂNICA } & \multicolumn{2}{|c|}{$\mathrm{pH}$} \\
\hline \multirow[t]{3}{*}{ Fonte } & \multirow{2}{*}{$\begin{array}{c}\text { Dose } \\
\mathrm{mg} \mathrm{kg}^{-1}\end{array}$} & $\mathrm{LV}$ & LR & \multirow[t]{2}{*}{$\mathrm{LV}$} & \multirow[t]{2}{*}{ LR } \\
\hline & & 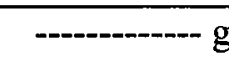 & 3 ----------- & & \\
\hline & 0 & $35,67 \quad \mathrm{Ac}^{(1)}$ & $24,33 \mathrm{Bb}$ & $5,0 \mathrm{Bc}$ & $5,6 \mathrm{Ad}$ \\
\hline $\mathrm{Cr}^{3+}$ & 250 & 38,00 Aabc & $24,00 \mathrm{Bb}$ & $4,8 \mathrm{Bd}$ & $5,1 \mathrm{Ae}$ \\
\hline $\mathrm{Cr}^{3+}$ & 1500 & $39,67 \mathrm{Aa}$ & $24,67 \mathrm{Bab}$ & $3,6 \mathrm{Ae}$ & $3,3 \mathrm{Bf}$ \\
\hline $\mathrm{Cr}(\mathrm{VI})$ & 250 & $38,00 \quad$ Aabc & $24,33 \mathrm{Bb}$ & $5,4 \mathrm{Bb}$ & $5,8 \mathrm{Ac}$ \\
\hline $\mathrm{Cr}(\mathrm{VI})$ & 1500 & 38,67 Aabc & $24,33 \mathrm{Bb}$ & $6,2 \mathrm{Aa}$ & $6,0 \mathrm{Bb}$ \\
\hline Cr-resíduo & 250 & 36,33 Abc & $24,33 \mathrm{Bb}$ & $5,3 \mathrm{Bb}$ & $6,0 \mathrm{Ab}$ \\
\hline Cr-resíduo & 1500 & $39,00 \mathrm{Aab}$ & $27,67 \mathrm{Ba}$ & $6,2 \mathrm{Ba}$ & $6,7 \mathrm{Aa}$ \\
\hline CV (\%) & & & & & \\
\hline
\end{tabular}

(1) Médias seguidas de mesma letra maiúscula não diferem na linha e médias seguidas de mesma letra minúscula não diferem na coluna pelo Teste de Tukey $(\mathbf{P}<0,05)$. 
Os valores de $\mathrm{pH}$ dos solos diminuíram significativamente em relação à testemunha quando foi aplicado crômio na forma trivalente $\left(\mathrm{CrCl}_{3} \cdot 6 \mathrm{H}_{2} \mathrm{O}\right)$, principalmente na dose de $1500 \mathrm{mg} \mathrm{kg}^{-1}$ e aumentaram em relação à testemunha quando foi aplicado crômio na forma hexavalente e resíduo de curtume. Assim como observado por Grove \& Ellis (1980) e Fortes et al. (1991), a aplicação de resíduo de curtume proporcionou a elevação do $\mathrm{pH}$ do solo. Essa elevação do $\mathrm{pH}$ pela adição de material orgânico tem sido uma constante em trabalhos envolvendo o uso de resíduos (Mattiazzo \& Glória, 1987).

\subsection{Movimentação de crômio em colunas de solo}

\subsubsection{Crômio}

Os dados obtidos para teores totais de crômio em amostras de solo submetidas à lixiviação são apresentados nas Tabelas 9 e 10.

$\mathrm{Na}$ análise dos resultados das Tabelas 9 e 10, observa-se que houve aumento da extração de crômio total com o aumento das doses do metal. As amostras de solo que receberam resíduo de curtume apresentaram teor de crômio total inferior ao das que receberam os sais contendo o elemento, possivelmente pela maior dificuldade na remoção do elemento quando aplicado via resíduo. Quanto aos solos, observa-se que, em alguns casos, foram encontrados teores de crômio total maiores no LR do que no LV (Tabela 9). Isso pode ser associado ao fato de o LV ter maior teor de matéria orgânica e maior CTC que o LR, o que aumenta a possibilidade de adsorção do $\mathrm{Cr}$ aos sítios de troca do solo, bem como reações de complexação com ácidos orgânicos solúveis, tais como ácido cítrico, DTPA, ácidos fúlvicos e matéria orgânica solúvel em água presente em extratos de solo. Nesses casos, dependendo do tipo de ligação estabelecida entre o crômio e as partículas do solo, sua extração se torna mais difícil (Alloway, 1990; Fischer et al., 1994).

O crômio total presente nos solos foi extraído em maior quantidade na camada 0 $20 \mathrm{~cm}$, principalmente nos casos nos quais predomina a forma trivalente $\left(\mathrm{Cr}^{3+}\right)$, indicando a pequena mobilidade do cátion (Tabela 10). 
Tabela 9 - Crômio total extraído em amostras de solos após lixiviação nas colunas.

\begin{tabular}{|c|c|c|c|}
\hline \multicolumn{2}{|c|}{$\mathrm{Cr}$ adicionado } & \multicolumn{2}{|c|}{ CRÔMIO TOTAL } \\
\hline \multirow[t]{3}{*}{ Fonte } & Dose & $\overline{L V}$ & LR \\
\hline & ------- & mg & - \\
\hline & 0 & $111,83 \mathrm{Ad}$ & $116,00 \quad \mathrm{Ac}^{(1)}$ \\
\hline $\mathrm{Cr}^{3+}$ & 250 & $413,33 \mathrm{Abc}$ & 247,17 Ac \\
\hline $\mathrm{Cr}^{3+}$ & 1500 & $1110,00 \mathrm{Ba}$ & $1395,67 \mathrm{Aa}$ \\
\hline $\mathrm{Cr}(\mathrm{VI})$ & 250 & 298,33 Acd & $326,00 \mathrm{Aa}$ \\
\hline $\mathrm{Cr}(\mathrm{VI})$ & 1500 & $1013,33 \mathrm{Aa}$ & $958,00 \mathrm{Ab}$ \\
\hline Cr-resíduo & 250 & 196,67 Ad & 356,67 Ac \\
\hline Cr-resíduo & 1500 & $555,00 \mathrm{Bb}$ & $950,00 \mathrm{Ab}$ \\
\hline
\end{tabular}

$\mathrm{CV}(\%)=19,99$

(1) Médias seguidas de mesma letra minúscula não diferem na coluna e médias seguidas de mesma letra maiúscula não diferem na linha pelo Teste de Tukey $(\mathrm{P}<0,05)$.

Tabela 10 - Crômio total extraído em amostras de solo após lixiviação nas colunas considerando as profundidades estudadas.

\begin{tabular}{|c|c|c|c|}
\hline \multicolumn{2}{|c|}{$\mathrm{Cr}$ adicionado } & \multicolumn{2}{|c|}{ CRÔMIO TOTAL } \\
\hline Fonte & Dose & Profundidade $0-20 \mathrm{~cm}$ & Profundidade $20-40 \mathrm{~cm}$ \\
\hline & - & mg kg & 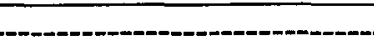 \\
\hline & 0 & $128,67 \mathrm{Ae}$ & 99,17 Ac \\
\hline $\mathrm{Cr}^{3+}$ & 250 & $510,67 \mathrm{Ad}$ & $149,83 \mathrm{Bc}$ \\
\hline $\mathrm{Cr}^{3+}$ & 1500 & $1826,67 \mathrm{Aa}$ & $679,00 \mathrm{Bb}$ \\
\hline $\mathrm{Cr}(\mathrm{VI})$ & 250 & $310,83 \mathrm{Ae}$ & 313,50 Ac \\
\hline $\mathrm{Cr}(\mathrm{VI})$ & 1500 & $909,83 \mathrm{Ac}$ & $1061,50 \mathrm{Aa}$ \\
\hline Cr-resíduo & 250 & 356,67 Ade & 196,67 Ac \\
\hline Cr-resíduo & 1500 & $1325,67 \mathrm{Ab}$ & $179,33 \mathrm{Bc}$ \\
\hline
\end{tabular}

(1) Médias seguidas de mesma letra minúscula não diferem na coluna e médias seguidas de mesma letra maiúscula não diferem na linha pelo Teste de Tukey $(\mathrm{P}<0,05)$. 
Nas Tabelas 11, 12 e 13 são mostrados os resultados referentes à distribuição das espécies de crômio presentes nos solos após a lixiviação.

Tabela 11 - Espécies de crômio presentes nos solos após a lixiviação nas colunas.

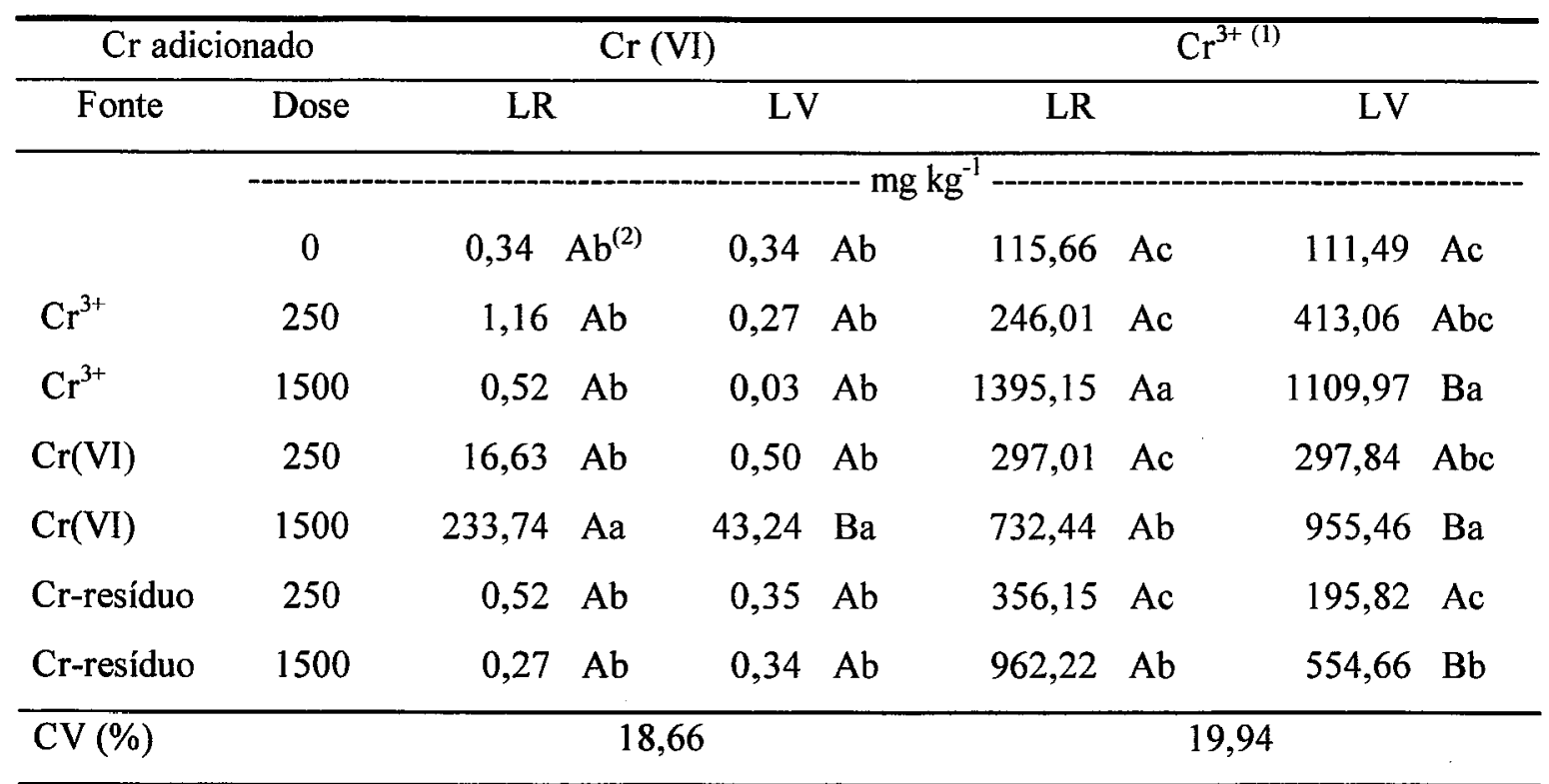

(1) Calculado pela diferença: $\mathrm{Cr}$ total (Tabela 9) - Cr(VI)

${ }^{(2)}$ Médias seguidas de mesma letra minúscula não diferem na coluna e médias seguidas de mesma letra maiúscula não diferem na linha pelo Teste de Tukey $(\mathrm{P}<0,05)$.

Considerando a distribuição das principais espécies de crômio presentes nos solos após a lixiviação, observa-se que o crômio trivalente foi a forma do elemento encontrada em maior quantidade, mesmo no caso dos solos que receberam a fonte de $\mathrm{Cr}(\mathrm{VI})$ como tratamento (Tabela 11). Isso indica que pode ter ocorrido redução de parte do crômio aplicado na forma hexavalente; como não foi observada a oxidação da matéria orgânica dos solos, possivelmente outra fonte doadora de eletrons $\left(\mathrm{Fe}^{2+}, \mathrm{Mn}^{2+}\right)$ participou dessa reação. Outra possibilidade é a adsorção do crômio hexavalente por partículas do solo carregadas positivamente (minerais de argila, óxidos de $\mathrm{Fe}$ e $\mathrm{Al}$, etc), como mencionado por Reisenauer (1982). O crômio na forma hexavalente ou $\mathrm{Cr}(\mathrm{VI})$ foi extraído em quantidade significativamente superior à testemunha somente nas amostras que 
receberam a aplicação de dicromato de potássio $\left(\mathrm{K}_{2} \mathrm{Cr}_{2} \mathrm{O}_{7}\right.$, dose 2$)$, o que indica não ter ocorrido oxidação do elemento quando aplicado ao solo na forma trivalente, apesar da presença de Mn nos solos estudados. O crômio trivalente não foi oxidado a crômio hexavalente provavelmente pela pequena quantidade de manganês presente no solo em relação à quantidade de crômio aplicada. Aquino Neto et al. (1997), trabalhando com solos de mesma classe textural (LV e LR) incubados com fonte de crômio trivalente $\left(\mathrm{CrCl}_{3} .6 \mathrm{H}_{2} \mathrm{O}\right)$ e lodo de curtume por 54 dias, detectaram a presença de $\mathrm{Cr}(\mathrm{VI})$ somente no LV e no primeiro dia de incubação.

Tabela 12 - Espécies de crômio presentes nos solos após a lixiviação nas colunas considerando as profundidades estudadas.

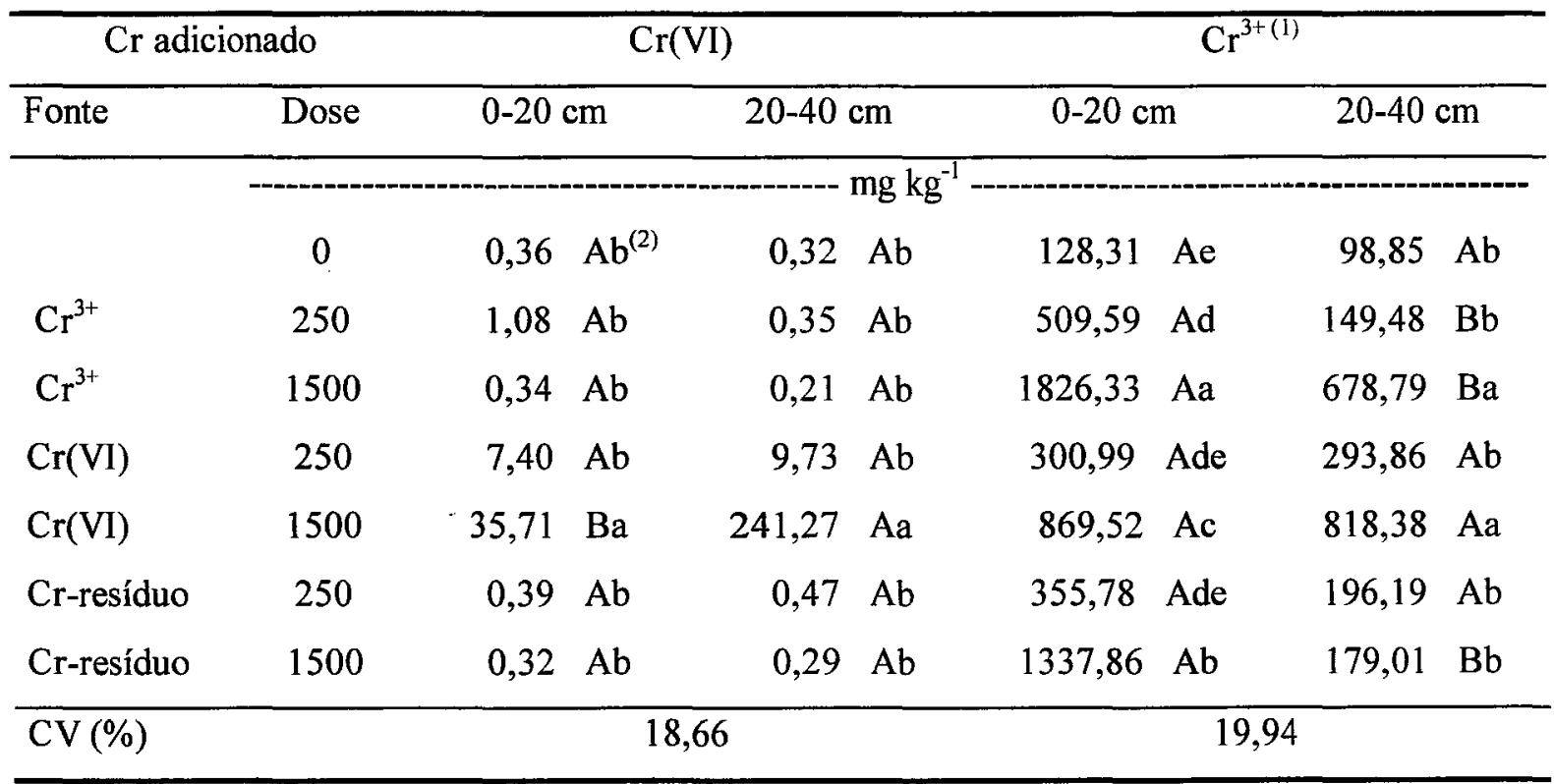

${ }^{\text {(1) }}$ Calculado pela diferença: $\mathrm{Cr}$ total (Tabela 10) - Cr(VI)

${ }^{(2)}$ Médias seguidas de mesma letra minúscula não diferem na coluna e médias seguidas de mesma letra maiúscula não diferem na linha pelo Teste de Tukey $(\mathrm{P}<0,05)$.

O crômio proveniente da aplicação do resíduo de curtume foi acumulado, em sua maior parte, na camada superficial, por estar, quase em sua totalidade, presente na forma trivalente ou mesmo por estar em forma pouco solúvel em água. Nesta camada, para 
todos os tratamentos, a quantidade de crômio extraída aumentou com a dose aplicada (Tabela 12).

Verifica-se que houve movimentação do crômio para a camada $20-40 \mathrm{~cm}$, principalmente, quando da adição do elemento sob a forma de $\operatorname{Cr}(\mathrm{VI})$, sendo que somente essa forma de crômio aumentou significativamente na camada $20-40 \mathrm{~cm}$ em relação à camada 0-20 cm, considerando os dois solos (Tabela 13).

Tabela 13 - Movimentação de crômio no solo durante o período de incubação considerando os solos e as profundidades estudadas.

\begin{tabular}{lrlllllllll}
\hline Solo & \multicolumn{3}{c}{$\mathrm{Cr}(\mathrm{VI})$} & \multicolumn{3}{c}{$\mathrm{Cr}^{3+}$} & \multicolumn{2}{c}{$\mathrm{Cr}$ total } \\
\hline & $0-20 \mathrm{~cm}$ & $20-40 \mathrm{~cm}$ & $0-20 \mathrm{~cm}$ & $20-40 \mathrm{~cm}$ & $0-20 \mathrm{~cm}$ & $20-40 \mathrm{~cm}$ \\
\cline { 2 - 10 } & & & & & & & & & & \\
$\mathrm{LR}$ & 11,15 & $\mathrm{Ba}^{(1)}$ & 61,19 & $\mathrm{Aa}$ & 825,08 & $\mathrm{Aa}$ & 347,67 & $\mathrm{Ba}$ & $834,67 \mathrm{Aa}$ & $408,05 \mathrm{Ba}$ \\
$\mathrm{LV}$ & 1,88 & $\mathrm{Ab}$ & 11,00 & $\mathrm{Ab}$ & 697,31 & $\mathrm{Ab}$ & 342,20 & $\mathrm{Ba}$ & $699,33 \mathrm{Ab}$ & $357,38 \mathrm{Ba}$ \\
\hline $\mathrm{CV}$ & \multicolumn{3}{c}{$18,66 \%$} & & & $19,94 \%$ & & $19,99 \%$
\end{tabular}

(1) Médias seguidas de mesma letra minúscula não diferem na coluna e médias seguidas de mesma letra maiúscula não diferem na linha pelo Teste de Tukey $(\mathrm{P}<0,05)$.

Os resultados das análises referentes ao teor de crômio presente no lixiviado aparecem na Figura 6. Nessa Figura observa-se que, das espécies de crômio apresentadas, a única a ser detectada no lixiviado estudado foi a hexavalente. Essa tendência da maior movimentação do crômio na forma de $\mathrm{Cr}$ (VI) foi também observada por Regitano (1978), confirmando o fato de que o $\mathrm{Cr}^{3+}$, por ser um cátion e, por isso, preferencialmente adsorvido às partículas do solo, torna-se menos passível de sofrer lixiviação. 


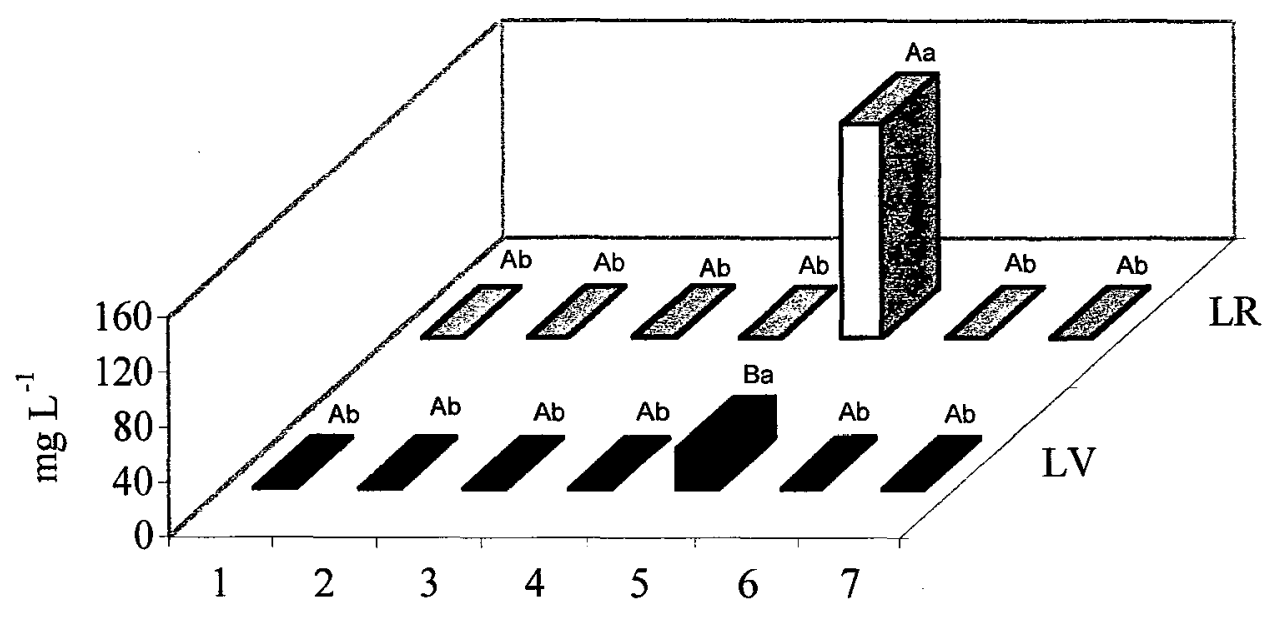

TRATAMENTOS

Figura 6 - Crômio lixiviado dos solos após 60 dias de incubação.

1) testemunha; 2) $\mathrm{Cr}^{3+}$ dose 1 ; 3) $\mathrm{Cr}^{3+}$ dose 2 ; 4) $\mathrm{Cr}(\mathrm{VI})$ dose 1 ; 5) $\mathrm{Cr}(\mathrm{VI})$ dose 2 ; 6) $\mathrm{Cr}$ resíduo dose 1;7) Cr-resíduo dose 2; dose $1=250 \mathrm{mg} \mathrm{kg}^{-1} \mathrm{Cr}$; dose $2=1500 \mathrm{mg} \mathrm{kg}^{-1} \mathrm{Cr}$ Letras maiúsculas - sem diferença significativa entre solos Letras minúsculas - sem diferença significativa entre tratamentos

\subsubsection{Cálcio e magnésio}

A seguir são apresentados os resultados das análises de cálcio e magnésio feitas nos lixiviados correspondentes a cada coluna de solo (Tabelas 14 e 15). Observa-se que houve lixiviação mais intensa de cálcio e magnésio nos tratamentos que receberam crômio trivalente, principalmente em relação à maior dose aplicada. Isso ocorreu, possivelmente, pela substituição do cálcio e magnésio presentes nos sítios de troca pelo crômio. Harter \& Baker (1977) relataram que os metais traços têm prioridade para serem adsorvidos especificamente, porque a seletividade de adsorção desses metais é da

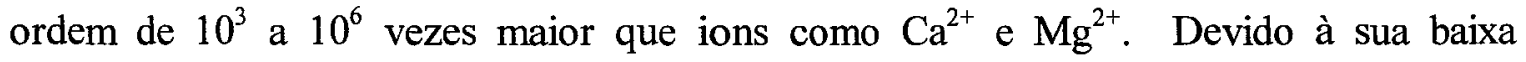


atividade na solução do solo, comparada com os cations mais abundantes (ex. $\mathrm{Ca}, \mathrm{Mg}$, $\mathrm{K}$ ), os metais traços tendem a ser adsorvidos especificamente caso ocupem uma grande porcentagem dos sítios de adsorção.

A aplicação de crômio na forma hexavalente e de resíduo de curtume não provocaram lixiviações significativas de $\mathrm{Ca} \mathrm{e} \mathrm{Mg}$ em relação à testemunha. Isso ocorreu provavelmente porque o crômio aplicado na forma de $\mathrm{Cr}(\mathrm{VI})$ permanece em parte na solução do solo, não ocupando os sítios de troca por ter comportamento aniônico; já o crômio fornecido pelo resíduo provavelmente não se encontra disponível ou apresenta baixa solubilidade. Houve maior lixiviação de $\mathrm{Mg}$ no $\mathrm{LV} \mathrm{em}$ relação ao $\mathrm{LR}$, provavelmente devido ao menor teor de óxidos do primeiro (principalmente óxidos de ferro e alumínio), proporcionando maior quantidade de crômio na solução do solo. 


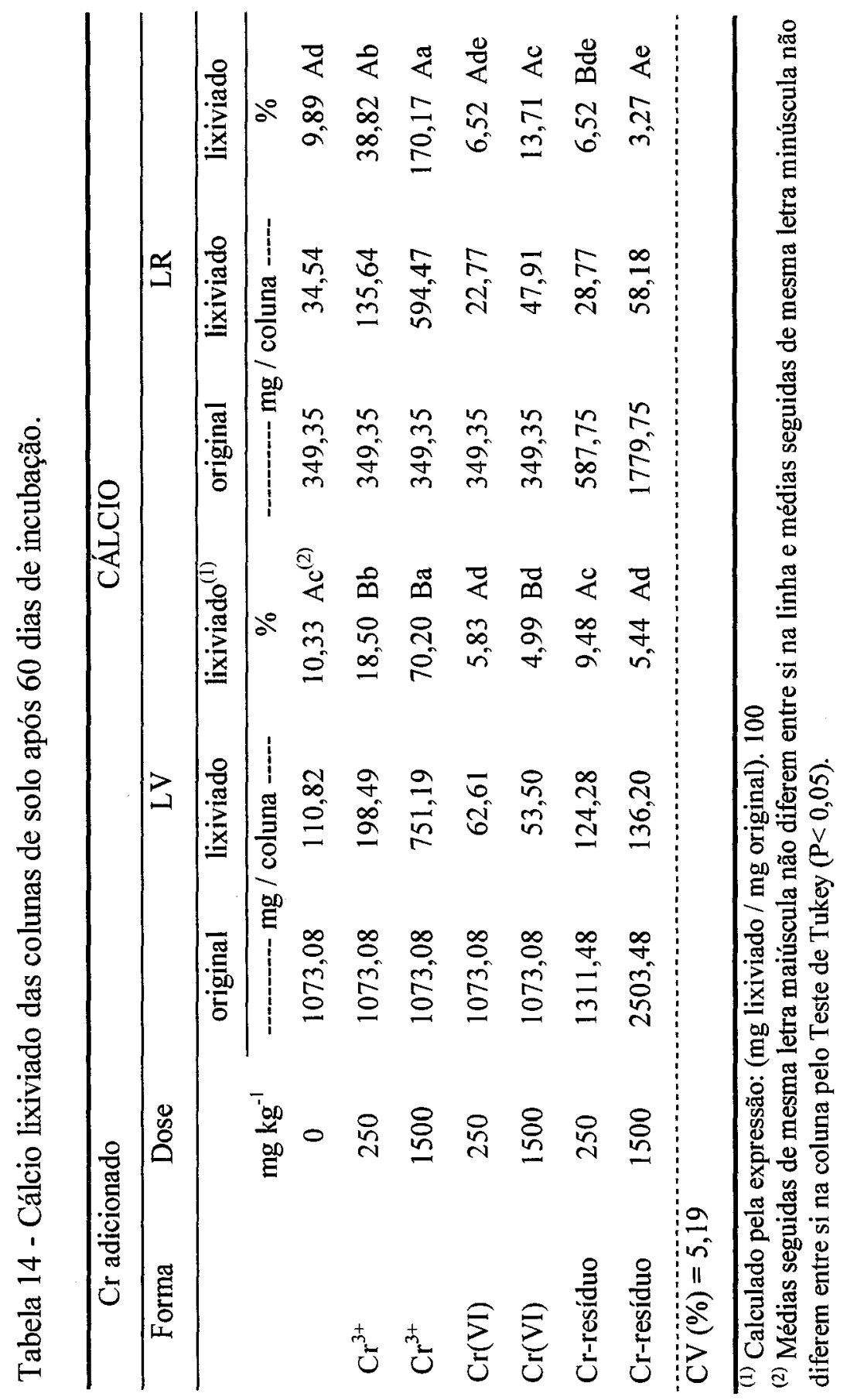




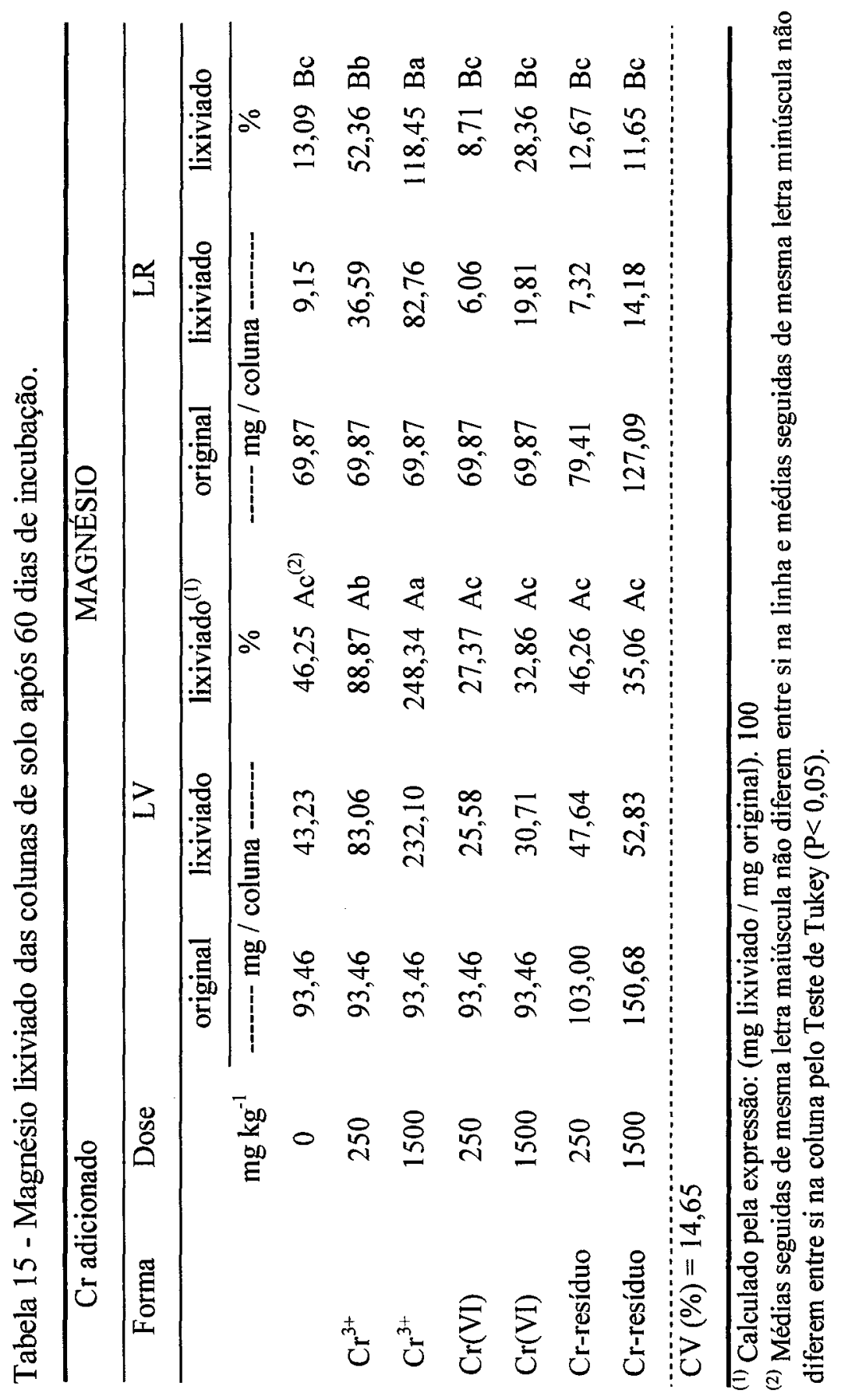




\subsubsection{Matéria orgânica e pH}

Os valores de $\mathrm{pH}$ e teores de matéria orgânica dos solos após lixiviação são mostrados na Tabela 16.

Tabela 16 - Teores de matéria orgânica e valores de $\mathrm{pH}$ dos solos após lixiviação nas colunas.

\begin{tabular}{|c|c|c|c|c|}
\hline \multicolumn{2}{|c|}{$\mathrm{Cr}$ adicionado } & \multirow{2}{*}{$\begin{array}{c}\text { MATÉRIA } \\
\text { ORGÂNICA }\end{array}$} & \multicolumn{2}{|c|}{$\mathrm{pH}$} \\
\hline Forma & Dose & & $\mathrm{LV}$ & LR \\
\hline & $\mathrm{mg} \mathrm{kg}^{-1}$ & $\mathrm{~g} \mathrm{dm}^{-3}$ & & \\
\hline & 0 & $24,33 \mathrm{~b}$ & $5,0 \mathrm{Ae}$ & $5,1 \mathrm{Ad}$ \\
\hline $\mathrm{Cr}^{3+}$ & 250 & $23,92 \quad b$ & $4,5 \mathrm{Bf}$ & $4,9 \mathrm{Ae}$ \\
\hline $\mathrm{Cr}^{3+}$ & 1500 & $25,75 \mathrm{ab}$ & $4,2 \mathrm{Ag}$ & $3,6 \mathrm{Bf}$ \\
\hline $\mathrm{Cr}(\mathrm{VI})$ & 250 & $24,67 \quad b$ & $5,5 \mathrm{Ac}$ & $5,4 \mathrm{Ac}$ \\
\hline $\mathrm{Cr}(\mathrm{VI})$ & 1500 & $24,50 \quad b$ & $6,1 \mathrm{Aa}$ & $5,7 \mathrm{Bb}$ \\
\hline $\mathrm{Cr}$ - resíduo & 250 & $25,83 a b$ & $5,2 \mathrm{Bd}$ & $5,4 \mathrm{Ac}$ \\
\hline $\mathrm{Cr}$ - resíduo & 1500 & 27,75 a & $5,7 \mathrm{Bb}$ & $5,9 \mathrm{Aa}$ \\
\hline CV (\%) & & 7,89 & & \\
\hline
\end{tabular}

${ }^{(1)}$ Médias seguidas de mesma letra minúscula não diferem entre si pelo Teste de Tukey $(\mathrm{P}<0,05)$.

Após a lixiviação, pode-se notar que o $\mathrm{pH}$ dos solos que receberam crômio trivalente diminuiu significativamente em relação à testemunha; nos solos que receberam os demais tratamentos ocorreu aumento significativo no valor de pH. Essa diminuição do pH pode ser explicada pela acidez proporcionada pelo elemento (Grove \& Ellis, 1980), aliada à lixiviação de $\mathrm{Ca}$ e $\mathrm{Mg}$, acarretando diminuição do índice de saturação por bases e, conseqüentemente, do valor de $\mathrm{pH}$.

Com relação à matéria orgânica presente nos solos após lixiviação, como não houve interação significativa entre os fatores estudados (fontes, solos e profundidades), 
foram apresentadas as médias gerais dos tratamentos. Pela análise desses dados, observase que somente nas colunas nas quais foi aplicado resíduo de curtume (dose $1500 \mathrm{mg} \mathrm{kg}^{-1}$ $\mathrm{Cr}$ ) os solos apresentaram aumento significativo de matéria orgânica em relação à testemunha. A aplicação de crômio não provocou diminuição do teor de matéria orgânica dos solos, como poderia ser esperado, devido ao elemento ser um agente oxidante. Convém salientar que os resultados de matéria orgânica foram obtidos pela multiplicação do teor de carbono orgânico pelo fator 1,724. Essa prática não é adequada em solos tratados com resíduos orgânicos; porém, considerando-se a velocidade de degradação do resíduo em 60 dias, optou-se por utilizá-la. 


\section{CONCLUSÕES}

A partir dos resultados discutidos concluiu-se que:

- A presença de crômio no resíduo de curtume não teve efeito prejudicial sobre a microbiota do solo;

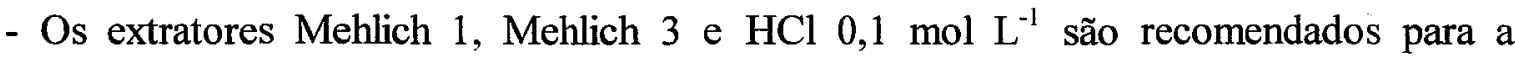
extração de crômio solúvel em solos contaminados com o elemento;

- Há necessidade do monitoramento de cálcio e magnésio quando da adição ao solo de resíduos contendo $\mathrm{Cr}$, para evitar possíveis deficiências nutricionais;

- O crômio é passível de sofrer lixiviação, principalmente quando na forma hexavalente, havendo a necessidade de se definir doses máximas permitidas para solos tropicais, a fim de que não ocorram prejuízos tanto ao solo quanto à cadeia alimentar. 


\section{REFERÊNCIAS BIBLIOGRÁFICAS}

ABREU, C.A.; ABREU, M.F.; RAIJ, B. van; SANTOS, W.R. Comparação de métodos de análise para avaliar a disponibilidade de metais pesados em solos. Revista Brasileira de Ciência do Solo, v.19, p.463-468, 1995.

ALLOWAY, B.J. Heavy metals in soils. New York: John Willey, 1990. cap.2, p.7-39: Soil processes and the behaviour of metals.

ANDERSON, J.P.E. Soil respiration. In: PAGE, A.L., MILLER, R.H., KEENEY, D.R. (Ed.) Methods of Soil Analysis. 2.ed. Madison: American Society of Agronomy, 1982. pt.2: Chemical and microbiological properties, cap.41, p. 831-845.

AQUINO NETO, V.; CAMARGO, O.A.; ANDRADE, J.C. Evolução do $\operatorname{Cr}(\mathrm{VI})$ em dois latossolos com diferentes teores de $\mathrm{Mn}$, após adição de lodo proveniente de estação de tratamento de curtume e de $\mathrm{CrCl}_{3}$. (compact disc). In: CONGRESSO BRASILEIRO DE CIÊNCIA DO SOLO, 26., Rio de Janeiro, 1997. Trabalhos. Rio de Janeiro: SBCS, 1997.

BARTLETT, R.J.; JAMES, B. Behaviour of chromium in soils: III. Oxidation. Journal of Environmental Quality, v.8, n.1, p.31-35, 1979. 
BARTLETT, R.J.; KIMBLE, J.M. Behavior of chromium in soils: I. Trivalent forms. Journal of Environmental Quality, v.5, n.4, p.379-383, 1976a.

BARTLETT, R.J.; KIMBLE, J.M. Behavior of chromium in soils: II. Hexavalent forms. Journal of Environmental Quality, v.5, n.4, p.383-386, 1976 b.

BENEDETTI, A.; CECCANTI, B.; CALCINAI, M.; TASSITANO, R. Decomposition of chromium-containing leather residues in a sandy soil. Suelo y Planta, v.1, n.1, p.15-24, 1991.

BERGKVIST, B.; FOLKESON, L.; BERGGREN, D. Fluxes of Cu, $\mathrm{Zn}, \mathrm{Pb}, \mathrm{Cd}, \mathrm{Cr}$ and $\mathrm{Ni}$ in temperate forest ecosystems. A literature review. Water, Air and Soil Pollution, v.47, p.217-286, 1989.

BRAILLE, P.M.; CAVALCANTI, J.E.W.A. Manual do tratamento de águas residuárias industriais. São Paulo: CETESB, 1979. cap.11, p.233-278: Curtumes.

CAMARGO, O A ; MONIZ, A.C.; JORGE, J.A ; VALADARES, J.M.A S. Métodos de análise química, mineralógica e física dos solos do Instituto Agronômico. Campinas: Instituto Agronômico, 1986. 94p. (IAC. Boletim Técnico, 106).

CHANDER, K.; BROOKES, P.C.; HARDING, S.A. Microbial biomass dynamics following addition of metal-enriched sewage sludges to a sandy loam. Soil Biology \& Biochemistry, v.27, n.11, p.1409-1421, 1995. 
FENDORF, S.E.; SPARKS, D.L.; FENDORF, M. Mechanism of aluminum sorption on birnessite: influences on chromium (III) oxidation. In: WORLD CONGRESS OF SOIL SCIENCE, 15., Acapulco, 1994. Anais. Acapulco: International Society of Soil Science, 1994. p.129-144.

FISCHER, W.R.; CRAM, S. Behavior and analysis of chromium in soils. In: WORLD CONGRESS OF SOIL SCIENCE, 15., Acapulco, 1994. Anais. Acapulco: International Society of Soil Science, 1994. p.467-482.

FORTES, P.N.; CAVALET, L.E.; SELBACH, P.A. Avaliação de microrganismos do solo em função da incorporação de lodo de curtume com cromo. In: CONGRESSO BRASILEIRO DE CIÊNCIA DO SOLO, 24., Porto Alegre, 1991. Resumos. Porto Alegre: SBCS, 1991. p.309.

FRITZE, H.; NIINE, S.; MIKKOLA, K.; MAKINEN, A. Soil microbial effects on a $\mathrm{Cu}-\mathrm{Ni}$ smelter in Southwestern Finland. Biology and Fertility of Soils, v.8, p.87-94, 1989.

GRIFFIN, R.A.; AU, A.K.; PROST, R.R. Effect of $\mathrm{pH}$ on adsorption of chromium from landfill-leachate by clay minerals. Journal of Environmental Science Health, v. A12, n.8, p.431-449, 1977.

GROVE, J.H.; ELLIS, G. Extractable chromium as relatades to soil $\mathrm{pH}$ and applied chromium. Soil Science Society of American Journal, v. 44, n.2, p.238-242, 1980.

HARTER, R.D.; BAKER, D.E. Applications and misapplications of the Langmuir equation to soil adsorption phenomena. Soil Science Society of America Journal, v. 41, p.1077-1080, 1977. 
JAMES, B.R. Hexavalent chromium solubility and reduction in alkaline soils enriched with chromite ore processing residue. Journal of Environmental Quality, v.23, p.227-233, 1994.

JENKINSON, D.S.; POWLSON, D.S. The effects of biocidal treatments on metabolism in soil. V. A method for measuring soil biomass. Soil Biology \& Biochemistry, v.8, n. , p.209-213, 1976.

KABATA-PENDIAS, A.; PENDIAS, H. Trace elements in soil and plants. Boca Raton: CRC Press, 1984. p.193-195: Trace metals.

KING, L.D. Soil heavy metals. In: CONGRESSO BRASILEIRO DE CIÊNCIA DO SOLO, 25., Viçosa, 1996. O solo nos grandes domínios morfoclimáticos do Brasil e o desenvolvimento sustentado. Viçosa: Sociedade Brasileira de Ciência do Solo, 1996. p.823-836

MATTIAZZO, M.E.; GLÓRIA, N.A. Effect of vinasse on soil acidity. Water Science and Technology, v.19, n.7, p.1293-1296, 1987.

MEHLICH, A. Mehlich 3 soil test extractant: a modification of Mehlich 2 extractant . Communications in Soil Science and Plant Analysis, v.15, p.1409-1416, 1984.

MEITES, L. General multiparametric curve fitting program CFT4. Postdam: Clarkson College of Technology, Department of Chemistry, Computing Laboratory, 1976. 206p.

NELSON, W.L.; MEHLICH, A.; WINTERS, E. The development, evaluation, and use of soil tests for phosphorus availability. Agronomy Journal, v. 4, p.153, 188, 1953. 
POMBO, L.C.A.; TEDESCO, M.J.; GIANELLO, C. Descarte de lodo de curtume em solo podzólico Vermelho-Amarelo. In: CONGRESSO BRASILEIRO DE CIÊNCIA DO SOLO, 24., Porto Alegre, 1991. Resumos. Porto Alegre: Sociedade Brasileira de Ciência do Solo, 1991. p.309.

RAIJ, B. van; QUAGGIO, J.A.; CANTARELLA, H.; FERREIRA, M.E.; LOPES, A.S.; BATAGLIA, O.C. Análise química do solo para fins de fertilidade. Campinas: Fundação Cargill, 1987, 170p.

REGITANO, M.A.B. Chromium in the environment with special emphasis on its behaviour in soils. Copenhagen: Royal Veterinary and Agricultural Universitiy, 1978. 63p. (Relatório Científico).

REISENAUER, H.M. Chromium. In: PAGE, A.L.; MILLER, R.H.; KEENEY, D.R. Methods of soil analysis. Madison: American Society of Agronomy, 1982. pt.2: Chemical and microbiological properties, cap.20, p.337-346.

SENESI, N.; SPOSITO, G. Characterization and stability of transition metal complexes of chestnut (Castanea sativa L.) leaf litter. Journal of Soil Science, v.40, p.461-472, 1989.

SOON, Y.K.; ABBOUD, S. Cadmium, chromium, lead and nickel. In: CARTER, M.R. Soil sampling and methods of analysis. Otawa: Canadian Society of Soil Science, 1993. cap13, p.101-108.

SUMMERS, A.G.; SILVER, S. Microbial transformations of metals. Annuary Review of Microbiology, v.32, p.637-672, 1978. 
TEDESCO, M.J. ; GIANELLO, C.; BISSANI, C.A.; BOHNEN, H.; VOLKWEISS, S.J. Análise de solo, plantas e outros materiais. 2.ed. Porto Alegre: UFRGS, Departamento de Solos,. 1995. 174p.

VITALE, R.J.; MUSSOLINE, G.R.; PETURA, J.C.; JAMES, B.R. Hexavalent chromium extration from soils: evaluation of alkaline digestion method. Journal of Environmental Quality, v.23, n.6, p.1249-1256, 1994.

WILLIAMS, D.E.; VLAMIS, J.; PUKITE, A.H.; COREY, J.E. Metal movement in sludge-amended soils: a nine-year study. Soil Science, v.143, n.2, p.124-131, 1987. 
APÊNDICE 
Tabela 1 - Esquema de análise de variância utilizado no experimento de movimentação de crômio em colunas de solo.

\begin{tabular}{|c|c|}
\hline Causas de variação & Graus de liberdade \\
\hline Fontes $(F)$ & 6 \\
\hline Solos (S) & 1 \\
\hline $\mathrm{F} \times \mathrm{S}$ & 6 \\
\hline Resíduo a & 28 \\
\hline (Parcelas) & (41) \\
\hline Profundidades $(\mathrm{P})$ & 1 \\
\hline $\mathrm{F} \times \mathrm{P}$ & 6 \\
\hline $\mathrm{S} \times \mathrm{P}$ & 1 \\
\hline $\mathrm{F} \times \mathrm{S} \times \mathrm{P}$ & 6 \\
\hline Resíduo b & 28 \\
\hline Total & 83 \\
\hline
\end{tabular}

Tabela 2. Concentrações máximas de crômio permitidas em solos recebendo resíduos orgânicos a $20 \mathrm{~cm}$ de profundidade.

\begin{tabular}{lc}
\hline \multicolumn{1}{c}{ País } & Concentração de crômio $\left(\mathrm{kg} \mathrm{ha}^{-1}\right)$ \\
\hline Estados Unidos (EPA) & 3000 \\
Alemanha & 200 \\
Holanda & 500 \\
Canadá (Ontario) & 210 \\
\hline
\end{tabular}

EPA - Environmental Protection Agency

Fonte: King (1996) 